\title{
ESTUDIO CLIMATOLÓGICO CON REGISTROS DE ALTA RESOLUCIÓN TEMPORAL EN CAMPAMENTO POSESIÓN (ENAP). MAGALLANES, CHILE.
}

\author{
CLIMATE STUDY WITH HIGH TEMPORAL RESOLUTION RECORDS IN CAMP \\ POSESION (ENAP). MAGALLANES, CHILE
}

\author{
Ariel Santana1 ${ }^{1}$ Carlos Olave $e^{2} \&$ Nicolás Butorovic ${ }^{3}$
}

\section{RESUMEN}

A fines de 2007 se instaló una estación automática de tiempo (AWS) en la planta Posesión (ENAP), al oriente de la región, en plena estepa magallánica. Se analiza la información recolectada durante el 2008 y se la compara con registros similares obtenidos en Punta Arenas. Se describen los montos y distribución de la radiación solar en diferentes rangos, al igual que el resto de variables atmosféricas. Se muestra que la temperatura del aire, la humedad relativa y el viento, dependen directamente de las variaciones de la radiación solar, tanto diaria como estacionalmente. La temperatura del suelo muestra una dependencia solo estacional con la energía solar, mientras que las variaciones de la presión atmosférica no parecen depender de las variaciones de esta. Con respecto a Punta Arenas, en Posesión la radiación en general es mayor a causa de la menor nubosidad y la precipitación es menor. Esto contribuye a una temperatura mayor, aunque también es responsable de esto la corriente principal del viento. Las velocidades del viento son mayores que en Punta Arenas, aunque las rachas instantáneas son menores lo cual muestra un viento menos arrachado que en Punta Arenas. Se compara las diversas variables en función de la dirección del viento y se compara con Punta Arenas.

\section{ABSTRACT}

By the end of 2007 an automatic weather station (AWS) in the Posesion plant was installed (ENAP), to the east of the region, in the magellanic steppe. The information collected during the 2008 is analyzed and compared with similar registries obtained in Punta Arenas. The amounts and distribution of the solar radiation in different ranks are described, like the rest of the atmospheric variables. It is shown that the temperature of the air, the relative humidity and the wind, depend directly on the variations of the solar radiation, daily as well as seasonally. The temperature of the ground only shows a seasonal dependency with solar energy, whereas the variations of the atmospheric pressure do not seem to depend on the variations of the radiation. In relation with Punta Arenas, the radiation in Posesión area is generally greater because of the lower, cloudiness and slight precipitation. This contributes to a greater temperature, although also the main current of the wind is responsible for this. The wind speeds are higher than in Punta Arenas, although the instantaneous gusts of wind are minor which show winds that are less gusty than in Punta Arenas. The diverse variables are compared depending on the wind direction and are compared to Punta Arenas.

\footnotetext{
${ }^{1}$ Instituto de la Patagonia. Universidad de Magallanes

${ }^{2}$ Centro de Estudios del Cuaternario (CEQUA)

${ }^{3}$ Doctorante Ciencias Atmosféricas Universidad Complutense de Madrid
} 


\section{INTRODUCCIÓN}

Durante diciembre del 2007, la Empresa Nacional del Petróleo (ENAP), asesorada por el laboratorio de climatología de la Universidad de Magallanes, instaló una estación de meteorológica de registro automático (AWS) en el campamento de Posesión, ubicado en $52^{\circ} 15^{\prime} 36.98^{\prime \prime}$ 'S y $68^{\circ} 56^{\prime}$ $7.41^{\prime} \mathrm{W}$, en plena estepa magallánica. Los registros regulares se comenzaron el 5 de diciembre de 2007 y se programaron para almacenar un valor medio de cada variable en periodos de media hora, que en el caso de la precipitación este valor constituye una sumatoria. Esta resolución temporal garantiza una capacidad de almacenamiento por un periodo de alrededor de 1,5 años de datos, que además de su independencia energética, se transforma en una estación totalmente automática de largo plazo.

La latitud en la cual se ubica esta localidad y de acuerdo con las condiciones astronómicas que gobiernan el planeta, la caracterizan en forma especifica respecto a otros puntos de la superficie terrestre. En efecto, en este paralelo la longitud del día y de la noche varían grandemente durante el año. Así, el día del solsticio de verano (21 de diciembre) la duración del día (horas de luz) llega a unas 18 horas, mientras que la oscuridad solo completa alrededor de 6 horas. En invierno esta situación se invierte y ahora son 18 las horas de oscuridad y solo 6 las horas de luz (Strahler 1979, Sola 1979, Long 1980).

Por su parte la luz del sol esta directamente relacionada con la cantidad de energía que este astro entrega a la superficie terrestre. La importancia de la radiación del sol es que es el motor que determina la dinámica de los procesos atmosféricos y el clima, y por tanto es la responsable de las variaciones de presión, de temperaturas, de viento, etc. (Retallack 1973). En esta latitud de Sudamérica la corriente principal del viento es del oeste (Santana 2006, 2007, Schneider et al. 2003) y la mayor parte de la superficie terrestre está constituida por océanos (Endlicher \& Santana 1988). En esta latitud el continente americano se reduce notablemente en una transecta oeste-este y son pocas las localidades que toman algunas características continentales, debido a esto.

El campamento de Posesión queda ubicado en la parte oriental de este sector continental, casi llegando al océano Atlántico, de manera que los vientos provenientes del oeste influyen notablemente en las condiciones climáticas de esta localidad.

Esta corriente del oeste, sumada a la morfología de la región define una serie de tipos climáticos característicos en Magallanes (Fuenzalida 1950, 1967, Pisano 1977, Weischet 1985, 1996). La corriente principal (del oeste) cuza estas áreas climáticas tomando características de cada una tipo climático, llegando en ultima instancia hasta la zona oriental de Magallanes, donde se encuentra la localidad de Posesión con características mas continentales que de carácter marítimo.

De esta forma, el sector de Posesión corresponde a un área plena de Estepa Fría, de acuerdo a los tipos climáticos de Magallanes definidos por diversos autores (Fuenzalida 1950, 1967, Pisano 1977), basados en la clasificación climática de W. Köppen. De acuerdo a estos autores, esta zona se define como del tipo Bsk'b, lo cual significa que un clima seco (B), de estepa (s), frío (k') y con, al menos, cuatro meses con temperatura media sobre $10^{\circ} \mathrm{C}$ (b). Esta área se caracteriza por presentar una precipitación inferior a la necesaria para el desarrollo natural del bosque. Una temperatura en general baja, con valores máximos sobre $25^{\circ} \mathrm{C}$ en pleno verano y de hasta $-10^{\circ} \mathrm{C}$ en invierno.

A pesar de su cercanía a grandes cuerpos de agua como el Estrecho de Magallanes y el océano Atlántico, condición que podría moderar la variación térmica tanto en forma diaria como estacional, esta localidad presenta una amplitud térmica mayor debido a la dirección principal del viento. En efecto, la masa de aire proveniente del océano Pacifico, tras

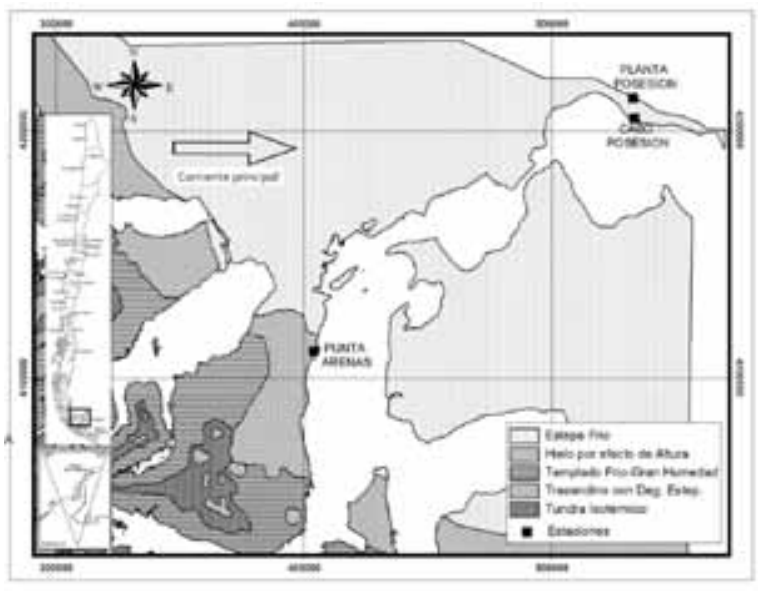

Fig. 1. Ubicación de la planta Posesión, climas presentes y dirección principal del viento. 
introducirse en la zona archipielágica y saturada de humedad, debe atravesar la cordillera de los Andes en esta latitud, sufriendo un enfriamiento adiabático que esto implica. Al descender a sotavento de la cordillera, el proceso adiabático se invierte y sufre un calentamiento producto del calor latente liberado en proceso de condensación, recuperando una temperatura mayor a la que traía la masa de aire al mismo nivel en el barlovento de la cordillera. Después de recorrer todo el sector patagónico continental, antes de llegar a la localidad de Posesión, la masa de aire se seca llegando al Atlántico con muy poca humedad y con temperaturas con características más continentales. La figura 1 muestra la ubicación de la planta Posesión, los tipos climáticos de un sector de Magallanes y la corriente principal del oeste.

Al igual que en otras localidades, en esta parte de Magallanes, las variaciones de la radiación solar en todas sus formas son sistemáticas y obedecen a condiciones astronómicas como el movimiento de rotación, produciendo una variación diaria de ésta y el movimiento de traslación, que junto a la inclinación del eje terrestre, produce una variación estacional de la energía solar sobre la superficie terrestre. Entonces esta energía es máxima a medio día y en verano, mientras que es mínima en la noche y madrugada, y en invierno.

Como en la mayoría de las superficies continentales, la parte de la radiación solar absorbida por esta, solo alcanza a penetrar una delgada capa de pocos centímetros, mientras que la componente transmitida de esta energía, es prácticamente nula en este medio. La componente reflejada depende del tipo de superficie (hielo, vegetación, suelo desnudo, etc.), y en algunos casos llega a ser la más importante en relación a su magnitud (Chuvieco 1990). En esta parte de la región la componente absorbida juega un papel importante.

Debido a la gran insolación en épocas de primavera y verano, que se ve maximizada por la escasa nubosidad, esta última, expresada en los escasos montos de precipitación anual que se alcanza en esta zona, hace que el suelo absorba gran cantidad de radiación solar, aumentando su temperatura y aumentando la temperatura del aire que pasa sobre él, proveniente principalmente del cuadrante oeste. Esto queda expresado en una mayor temperatura hacia horas de mediodía y en verano, mientras que en invierno esta son menores a las obtenidas en localidades mas cerca del Pacifico, como por ejemplo, Punta Arenas.

La humedad relativa del aire, que expresa la distancia desde las condiciones reales del contenido de humedad, a las condiciones de saturación, depende de de manera importante de la temperatura. Así, para un determinado contenido de humedad en el aire, mientras mayor es la temperatura, mayor es la distancia al punto de saturación, es decir, la humedad relativa del aire disminuye. Cuando la temperatura baja, la humedad relativa aumenta, disminuyendo la distancia a las condiciones de saturación del aire. En condiciones de saturación la humedad relativa alcanza al $100 \%$. Y se alcanza cada vez que llueve

De esta manera, al igual que la temperatura y como una dependencia de esta, la humedad relativa del aire muestra variaciones similares a lo largo del día y a través del año. Esto hace que la humedad baje hacia horas del mediodía y en las épocas más cálidas del año, como a fines de primavera, verano y comienzos de otoño. Al bajar la radiación solar en la noche y en invierno, también lo hace la temperatura, la cual trae como consecuencia que la humedad contenida en el aire en forma de vapor, se acerque al punto de saturación aumentando su valor. De esta forma los valores mas altos de humedad aparecen en horas de la noche y en invierno

La mayoría de las variables meteorológicas de Magallanes presentan diferencias importantes en sus distintas ubicaciones, inclusive entre localidades espacialmente cercanas. (Pisano 1977). Buenos ejemplos de esto lo constituyen la precipitación, la nubosidad, la humedad, la temperatura y la insolación. Las excepciones a esto son el viento y la presión atmosférica, variables que se comportan mas o menos similares en toda la región..

El viento es uno de los parámetros atmosféricos más característicos de la región de Magallanes, debido a la intensidad con que se manifiesta en determinadas épocas y circunstancias del año, y de la dirección de donde proviene esta masa.

La región de Magallanes queda ubicada en zona donde la circulación general de la atmósfera tiene características muy particulares. La zona sur del anticiclón semipermanente del Pacifico sur, al igual que la zona norte del anticiclón antártico, provocan una corriente proveniente del oeste en las latitudes de Magallanes. La zona de encuentro de estas masas de aire define el llamado frente polar y esta zona es 
la que gobierna casi todo el año el clima regional. En ocasiones el anticiclón subtropical se desplaza hacia el sur, apretando las isobaras contra el anticiclón antártico, provocando intensos temporales de viento que afectan toda la región. Sin embargo, esta corriente principal se ve afectada localmente por condiciones morfológicas (canales, cerros, etc.) y sufre modificaciones locales como cambios en la velocidad y/o la dirección del viento en las diversas localidades. La dinámica de estos centros re repite de año en año de manera similar y provoca ciertas variaciones en los viento haciendo en algunos casos predominios importantes del nnoroeste y en otros años predominios importantes del suroeste, aunque la principal dirección en todos locasos es del oeste.

El viento es sensible tanto a la rugosidad del terreno como a la altura de medición (Valko 1978), de manera que para hacer una comparación entre localidades es necesario estandarizar la altura de medición con el objeto de que la comparación con otras localidades tenga validez. De esta manera, los registros se estandarizan a $10 \mathrm{~m} \mathrm{~s}$. n. s.

Debido a la escala con que se mueven los centros dinámicos de la atmosfera y al tamaño de estos, la presión atmosférica, presenta leves diferencias entre localidades dentro de la región de Magallanes, de manera que los valores de presión obtenidos en una estación determinada no difieren mayormente de otra localidad cualquiera y las diferencias existentes entre ellas se deben especialmente a la diferencia de altitud de las estaciones

\subsection{Antecedentes climáticos previos}

De acuerdo a la información histórica disponible en esta localidad ${ }^{1}$, la precipitación alcanza un promedio anual de unos $300 \mathrm{~mm}$ y aunque todos los meses presentan precipitaciones, el promedio de más de 30 años en cabo Posesión muestra que los montos tienden a disminuir levemente en invierno y a comienzos de la primavera. Los meses de mayor promedio corresponden a enero, marzo y diciembre, en tanto que los más secos son julio, agosto, septiembre y octubre. Por otro lado, la escasa información que se dispone, muestra que la temperatura media anual llega a los $8,0^{\circ} \mathrm{C}$, presentando cuatro meses con promedios superiores a $10^{\circ}$ C. Este aspecto es importante ya que establece una diferencia climática notable respecto a las zonas del occidente patagónico. El mes más cálido es enero, mientras que el más frío es julio. Algunos autores (Fuenzalida 1950, 1967; Pisano 1977), basados en estas características termo-pluviométricas y de acuerdo con la clasificación climática de Köppen, han definido a esta área como Clima Estepa Frío $\left(\mathrm{BSk}^{\prime} \mathrm{c}\right)^{2}$. La Tabla 1 resumen los valores medios mensuales de temperatura y precipitación de la localidad de Posesión.

TABLA 1. Resumen de valores medios mensuales históricos.

\begin{tabular}{cccccccccccccc}
\hline & ENE & FEB & MAR & ABR & MAY & JUN & JUL & AGO & SEP & OCT & NOV & DIC & AÑO \\
\hline T.med & 13.4 & 13.1 & 10.9 & 8.7 & 5.7 & 3.2 & 2.6 & 3.7 & 5.7 & 8.1 & 9.6 & 11.7 & 8.0 \\
T.máx & 31.0 & 26.0 & 23.0 & 22.0 & 15.0 & 12.0 & 10.0 & 13.0 & 19.0 & 24.0 & 24.0 & 27.0 & 31.0 \\
T.mín & 2.0 & 1.5 & -1.5 & -2.0 & -9.0 & -9.0 & -10.0 & -9.5 & -6.0 & -5.0 & -2.5 & -1.0 & -10.0 \\
Prec. & 35.0 & 24.9 & 35.3 & 30.0 & 26.8 & 22.3 & 20.0 & 17.9 & 15.4 & 15.1 & 23.4 & 35.0 & 301.1 \\
\hline
\end{tabular}

Los datos de temperatura están basados en mediciones realizadas en la planta Posesión y corresponden al periodo 1975 - 1979, mientras que la precipitación corresponde a las mediciones en cabo Posesión (faro) y comprenden un periodo más extenso, aunque más antiguo, que va desde
1913 a 1951.

Otras variables disponibles para esta área corresponden a la presión atmosférica y el viento. La primera de estas corresponde a mediciones realizadas en la planta, en el periodo 1975-1979, en tanto que los registros del viento, correspondientes

\footnotetext{
${ }^{1}$ Archivo de datos climáticos. PINDOC. Área de Geociencias. Instituto de la Patagonia .UMAG

${ }^{2}$ www.umag.cl/facultades/instituto/climatologia/clima_magallanes.php
} 
a mediciones realizadas en la Planta, abarcan un periodo inferior a un año.

La información de viento disponible para este punto geográfico no es suficiente para dar una caracterización anual. Sin embargo, con estos antecedentes fue posible obtener una rosa de frecuencias que aproxima el comportamiento del

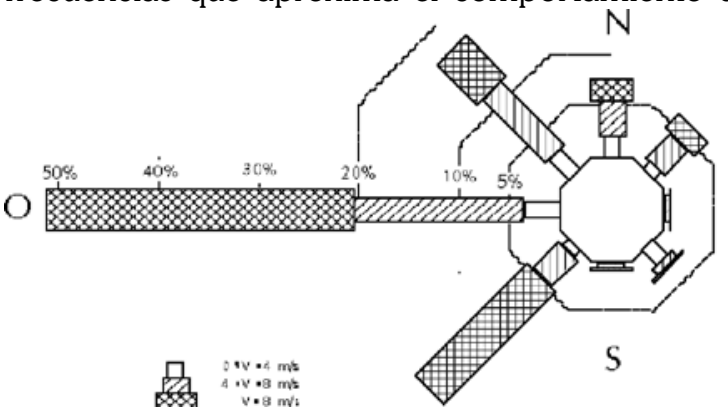

Fig. 2. Rosa de frecuencia de vientos de Posesión.

En la figura 2 se observa un alto predominio del cuadrante oeste, siguiendo en importancia el suroeste y noroeste. De la figura también se desprende que las mayores velocidades corresponden a la dirección oeste, seguidas del suroeste y del noroeste, haciéndose mínimas estas en las direcciones este, sureste y sur.

\section{MATERIAL Y MÉTODOS}

\subsection{La estación de registro automática (AWS)}

La estación meteorológica corresponde a un E equipo autónomo fabricado por Campbell Scientific Inc., cuyo modelo en la unidad captadora y almacenadora de datos (Datalogger) es el CR1000³. Entre sus principales características destacan sus $4 \mathrm{MB}$ de SRAM para el almacenamiento de datos y sus variadas formas de comunicación con el usuario, entre las que destaca la comunicación vía telefónica mediante un modem, la cual permite consultar y extraer información de la estación a distancia. La estación dispone se los siguientes sensores para la medición de variables:

TABLA 2- Sensor y modelo para la medición de variables atmosféricas

\begin{tabular}{|c|c|}
\hline Sensor & Modelo \\
\hline 1 Piranómetro Licor & LI190SB \\
\hline 1 Sensor de Radiación Apogge & CS300 \\
\hline 1 Sensor de Radiación Solar Neta & NR-LITE \\
\hline 1 Sensor de Temperatura y Humedad & HMP45C-L11 \\
\hline 1 Sensor de temperatura de suelo & 107-L20 \\
\hline 1 Pluviómetro & TE $525 \mathrm{~mm}$ \\
\hline 1 Barómetro Vaisala & CS105 \\
\hline 1 Anemómetro & 05103 \\
\hline 1 Sensor de Radiación Ultravioleta UVB & PMA 1102 \\
\hline 1 Sensor de altura de nieve & SR50 \\
\hline
\end{tabular}

La energía solar está compuesta por una completa gama de longitudes de onda correspondientes al espectro electromagnético (Strahler 1979, Chuvieco 2002). Esta energía se mide en diversos rangos según la utilidad que se requiera. Así, los más utilizados corresponden al 0,4 a 0,7 $\mu \mathrm{m}$ (radiación PAR), de 0,3 a 1,1 $\mu \mathrm{m}$ (radiación global) de 0,2 a $100 \mu \mathrm{m}$ (radiación neta) y de 0,25 a 0,37 $\mu \mathrm{m}$ (radiación ultravioleta).

Para la medición de la radiación PAR (Photosynthetically Active Radiation), que es la radiación del sol que se encuentra contenida en el rango visible del espectro solar, se utilizó un sensor LI-COR modelo LI 190SB ${ }^{4}$. Esta parte de la radiación solar es la utilizada por las plantas en el proceso de fotosintesis e involucra tanto términos de fotones (cantidad de luz) como términos de energía, por lo que se puede expresar en unidades de energía (W $\mathrm{m}^{-2}$ ) o en unidades de flujo de fotones fotosintéticos, es decir, en cuantos por unidad de tiempo y por unidad de área $\left(\mathrm{mol} \mathrm{s}^{-1} \mathrm{~m}^{-2} \mathrm{o}\right.$ en $\left.\mathrm{E} \mathrm{s}^{-1} \mathrm{~m}^{-2}\right)$. La unidad más utilizada en las ciencias de las plantas ha sido el Einstein (E). Sin embargo, ahora se recomienda el uso del mol, desde que esta es una unidad acep- 
tada en el sistema internacional (Page \& Vigoureux 1977). La cantidad de fotones en un mol es igual a la cantidad de fotones en un Einstein. Un mol de fotones generalmente se utiliza para designar el número de Avogadro de fotones (6,022 x 1023 fotones).

La radiación global es aquella que considera la radiación directa (haz de luz solar) más la difusa (luz proveniente de la bóveda celeste). El rango de medición es de los $0,3 \mu \mathrm{m}$ a los $1,1 \mu \mathrm{m}$, es decir, toma la parte visible y la parte infrarroja del espectro solar, esta última, manifestada en forma de calor. El sensor de radiación global es un CS300 de la Campbell Sci. y mide la radiación solar entrante a través de un detector fotovoltaico de silicio, montado en un cabezal coseno-corregido. La salida del detector es una corriente que es convertida a voltaje por un potenciómetro en la cabeza del sensor. La resistencia del potenciómetro se ajusta cuando el sensor se calibra de forma que todos los sensores tienen la misma sensibilidad de salida ${ }^{5}$.

Otra medida de la radiación solar es la radiación neta, que esta referida a un balance de energía, es decir, con un sensor se mide la energía que entra a la superficie de la tierra y otro sensor mide la energía que emana de ella, obteniéndose un balance entre la energía entrante y saliente. La radiación entrante consiste en la radiación directa (haz de luz del sol) y la radiación difusa sumada a la irradiancia de onda larga proveniente del cielo. La radiación saliente consiste en la radiación solar reflejada por la superficie, más la componente de radiación de onda larga emitida por la tierra. El sensor de radiación neta es un sensor Campbell modelo NR Lite, constituido por una termopila de alto rendimiento que mide la suma algebraica de las entradas y salidas de todas las ondas de la radiación solar ${ }^{6}$.

Cabe destacar aquí que todas las mediciones de radiación solar están referidas a una superficie horizontal, de manera que se debe tener en cuenta el ángulo que forman los rayos solares con esta superficie al momento de tomar las muestras.

Para la temperatura y la humedad relativa se utilizó un sensor HMP45C-L11. El HMP45C es un sensor preciso que mide la temperatura y humedad relativa con una precisión de $0,1^{\circ} \mathrm{C}$ y 1 $\%$ respectivamente, fabricado por Vaisala Inc. Es ideal para el registro de largo plazo, sin necesidad de mantención. El sensor utiliza un polímero capacitivo $\mathrm{H}$ chip para medir la humedad relativa y una PRT para medir la temperatura. El rango de medición de la humedad relativa es de $0,8 \%$ a $100 \%$ y funciona dentro de un rango de temperatura de $-40^{\circ} \mathrm{C}$ a $60^{\circ}$ C. El sensor de temperatura trabaja en un rango de $-39,2^{\circ} \mathrm{C}$ a $60^{\circ} \mathrm{C}^{7}$.

La medición de la temperatura del suelo se realizó a $30 \mathrm{~cm}$. de profundidad y se utilizó un sensor Campbell 107-L, que consta de un termistor encapsulado en una carcasa cilíndrica de aluminio. Su rango de medición es de los $-35^{\circ} \mathrm{C}$ a los $50^{\circ} \mathrm{C}^{8}$.

La precipitación se midió con un pluviómetro fabricado por Texas Electronic, modelo TE525MM y que mide incrementos de precipitación de $0,1 \mathrm{~mm}$, mediante un sistema de balancín que actúa cuando entra agua por el embudo activando una señal al Capturador-almacenador (Datalogger) cada vez que se llena una parte de este balancín, marcando incrementos de 0,1 mm, en función del tiempo?.

Para la medición de la presión atmosférica se utilizó un sensor CS105. Este barómetro utiliza un sensor capacitivo de silicón de la Vaisala para medir la presión atmosférica en un rango entre 600 a 1020 hecto-Pascales su precisión es de $0,5 \mathrm{hPa}$ a $20{ }^{\circ} \mathrm{C}$, de $1,5 \mathrm{hPa}$ entre los $0{ }^{\circ} \mathrm{C}$ a $40{ }^{\circ} \mathrm{C}$ y de 2,5 $\mathrm{hPa}$ en los $-20^{\circ} \mathrm{C}$ y $45^{\circ} \mathrm{C}^{10}$.

El viento se midió con un anemómetro Young modelo 05103. El instrumento está hecho de plástico protegido contra la radiación UV con acero inoxidable y con accesorios de aluminio anodizado. Este anemómetro modelo 05103 es un sensor de viento resistente de alto rendimiento. Su simplicidad de construcción, resistente a la corrosión, lo hace ideal para una amplia gama de aplicaciones de medición de viento. El sensor de velocidad es una hélice de cuatro paletas helicoidales. La rotación de la hélice produce una señal de voltaje de corriente alterna de onda sinusoidal, con frecuencia directamente proporcional a la velocidad del viento. El sensor de dirección del viento es una ligera y resistente veleta con un aspecto lo suficientemente pequeño para asegurar la fidelidad en las fluctuaciones del viento en buenas condiciones de tiempo. El ángulo de la veleta es detectado por un potenciómetro de precisión ubicado en una cámara sellada. Con una cantidad conocida de tensión de excitación aplicada

\footnotetext{
${ }^{5}$ www.campbellsci.com/documents/manuals/cs300.pdf

${ }^{6}$ www.campbellsci.com/documents/manuals/nr-lite.pdf

${ }^{7}$ www.campbellsci.com/hmp 45c-l

${ }^{8}$ www.campbellsci.com/107-1

${ }^{9}$ www.campbellsci.com/te $525 \mathrm{~mm}-1$

${ }_{10}$ www.campbellsci.com/documents/manuals/retired/cs105.pdf
} 
al potenciómetro, el voltaje de salida es directamente proporcional al ángulo de la veleta. Un anillo de orientación correcta de montaje asegura el reajuste de la dirección cuando el instrumento se desmonta de referencia se elimina para el mantenimiento. El rango de medición es entre 0 y $100 \mathrm{~m} / \mathrm{s}$, con una precisión de $0,3 \mathrm{~m} / \mathrm{s}$ para la velocidad y de $0360^{\circ}$ para la dirección con precisión de $3^{\circ 11}$.

La tabla 2 muestra los sensores para la medición de cada variable. Los sensores de radiación UVB y de altura de nieve, no generaron información correcta.

Para la comunicación con la estación, el fabricante suministra el software Campbell PC400, a través del cual se configura la estación y se baja la información de un periodo determinado para su análisis. De acuerdo a la configuración definida previamente, la estación toma muestras cada 10 segundos, evaluando los datos y almacenándolos en registros de 30 minutos, conformando un archivo de valores medios de todas las variables cada media hora. Este archivo se denomina CR100_Table1.txt. Adicionalmente, los datos capturados se procesan para generar un segundo archivo de valores diarios, en los que se incluye los valores extremos (máximas, mínimas y totales) de 24 horas. El archivo se denomina CR100_Table 2.txt. Estos archivos tienen formato de texto, de manera que para leerlos se debe hacer una importación de los daros desde la planilla Excel y transformarlos a valores numéricos para procesarlos.

El archivo CR100_table 1 contiene el re- gistro de todas las variables en periodos de media hora y para todo el año 2008. Esto significa que para cada variable se tienen 17.568 datos (2008 es bisiesto) y si consideramos que la estación monitores alrededor de 10 variables, estamos tratando con un archivo de unos 175.680 datos. En el saco del archivo de datos diarios CR100_Table2 se trata de un volumen menor de datos que alcanza a unos 3660. Esta configuración permite almacenar hasta un año y medio de información. Naturalmente esta configuración se puede cambiar, por ejemplo a intervalos de una hora, lo cual permitiría un periodo de almacenamiento de tres años.

\subsection{Procesamiento y análisis}

Para el proceso y análisis de los datos se utilizó la planilla Excel y el programa estadístico STATISTICA, mientras que para los gráficos de isolíneas se utilizó el SURFER.

Las variables de tipo escalar se procesaron en Excel formando tablas de periodos diarios, obteniéndose con ellos los valores medios mensuales. En el caso de la variable vectorial (viento). En lo referente a los valores de velocidad, se trató de la misma forma que una variable escalar y en el análisis de su predominancia junto a sus valores de velocidad, mediante el STATISTICA se generaron histograma bi-variados que relacionaron los rangos de velocidades (cada $1 \mathrm{~m} / \mathrm{s}$ ) en función de cada dirección y su frecuencia, para cada mes. Con esto fue posible construir una rosa de frecuencia de vientos con variados rangos de velocidad.

\subsection{Energía del viento}

Para la evaluación de la energía del viento se utilizó la siguiente metodología planteada por diversos autores (Redlinger et al. 2002, Mathew 2006). El viento es una masa de aire en movimiento y por lo tanto su energía se puede evaluar como energía cinética, es decir como:

$$
\mathrm{E}_{\mathrm{c}}=1 / 2 m v^{2}
$$

donde, $m$ : es la masa del aire (en $\mathrm{kg}$ )

$v$ : es la velocidad de desplazamiento de esta masa $\left(\mathrm{m} \mathrm{s}^{-1}\right)$

$E_{c}$ : es la energía cinética del aire (en Joules o Watts)

Por su parte se sabe que la densidad es:

$$
\delta=m / V \quad\left(\mathrm{~kg} \mathrm{~m}^{-3}\right)
$$

${ }^{11}$ www.campbellsci.co.uk/index.cfm?id=511 
y el volumen $(V)$ se puede expresar como:

$$
V=A v
$$

donde, A: es un área cualquiera, perpendicular a la velocidad en $\mathrm{m}^{2}$.

$v$ : es la velocidad de la masa de aire en $\mathrm{m} \mathrm{s}^{-1}$.

$V$ : es el volumen expresado en $\mathrm{m}^{3} \mathrm{~s}^{-1}$.

Reemplazando en (2) y despejando la masa, nos queda,

$$
m=\delta A v\left(e \mathrm{~kg} \mathrm{~s}^{-1}\right)
$$

Reemplazando en (1) se tiene

$$
E_{c} / s=\delta A v v^{2}=1 / 2 \delta A v^{3} \text { (Watt) }
$$

A este término $\left(E_{c} / s\right)$ se le denomina Potencia del viento.

Si se divide por el área (A), ambos términos y se multiplica por el número de horas (h) con velocidad $\mathrm{v}$, obtenido a partir de la frecuencia absoluta de los datos de velocidad del viento, se obtiene la energía del viento (E) por unidad de área, mediante:

$$
E=1 / 2 \delta v^{3} h
$$

Donde E: es la energía del viento en Watt-h/m²

$v$ : es la velocidad del viento en $\mathrm{m} \mathrm{s}^{-1}$

$\delta$ : es la densidad del aire en $\mathrm{kg} \mathrm{m}^{-3}$

$h$ : es el numero de horas con velocidad $v$.

Para la densidad $(\Delta)$ del aire se utiliza el valor $1,2 \mathrm{~kg} \mathrm{~m}^{-3}$, pero éste puede ser afinado más exactamente a partir de los valores medios de temperatura y presión del lugar, mediante la ley universal de los gases perfectos.

donde,

$$
\delta=P / R T
$$

$P$ : es la presión atmosférica (en $\mathrm{hPa}$ )

$R$ : es la constante de gas estándar para aire seco (en $\mathrm{J} /{ }^{\circ} \mathrm{K} \mathrm{kg}$ )

$T$ : es la temperatura $\left(e^{\circ} \mathrm{K}\right)$

Así, la densidad local se puede calcular haciendo:

$$
\delta=0,3488 \text { (Presión atmosférica/Temperatura) }
$$

Para hacer una comparación entre localidades es necesario estandarizar la altura de medición con el objeto de que la comparación con otras localidades tenga validez. De esta manera, los registros se estandarizan a $10 \mathrm{~m} \mathrm{~s}$. $\mathrm{n}$. $\mathrm{s}$. 


\section{RESULTADOS Y DISCUSIÓN}

Los archivos de datos extraídos del Datalogger y los cuales se analizan en este trabajo, corresponden al CR1000_Table1 con un tamaño de $4.235 \mathrm{~Kb}$ y al CR1000_Table 2 con un tamaño de $234 \mathrm{~Kb}$. Los archivos de inician el 5 de diciembre de 2007 y finalizan el 12 de abril de 2009. Para efectos de este estudio se analizó la información correspondiente al año 2008.

\subsection{Radiación solar}

\subsubsection{Radiación PAR}

La parte visible de la radiación solar, llamada también radiación PAR presentó un promedio anual de $297 \mu \mathrm{mol} \mathrm{s}{ }^{-1} \mathrm{~m}^{-2}$, equivalente a $64,6 \mathrm{~W}$ $\mathrm{m}^{-2}$. El comportamiento mensual es estacional, es decir, los promedios más altos se producen en los meses de primavera y verano en tanto que los de menos valor ocurren en invierno. En el 2008 el mayor promedio lo presentó diciembre con $589,4 \mu \mathrm{mol} \mathrm{s}^{-1} \mathrm{~m}^{-2}$, seguido de enero con 568,4 $\mu \mathrm{mol} \mathrm{s} \mathrm{m}^{-1}$. Los meses de menor radiación PAR promedio fueron junio y julio, con valores de 73,8 $\mu \mathrm{mol} \mathrm{s}{ }^{-1} \mathrm{~m}^{-2}$ y $78,6 \mu \mathrm{mol} \mathrm{s} \mathrm{m}^{-2}$ respectivamente.

TABLA 3. Radiación solar 2008 en Posesión.

\begin{tabular}{lrrrrrrr}
\hline & \multicolumn{2}{c}{$\begin{array}{c}\text { Radiación PAR } \\
\left(\mu \mathrm{mol} \mathrm{s}^{-1} \mathrm{~m}^{-2}\right)\end{array}$} & \multicolumn{2}{c}{$\begin{array}{c}\text { Radiación Global } \\
\left(\mathrm{W} \mathrm{m}^{-2}\right)\end{array}$} & \multicolumn{3}{c}{$\begin{array}{c}\text { Radiación Neta } \\
\left(\mathrm{W} \mathrm{m}^{-2}\right)\end{array}$} \\
\hline Media & \multicolumn{1}{c}{ Máxima } & Media & Máxima & Máxima & \multicolumn{1}{c}{ Mínima } & Media \\
\hline FEBRE & 568,4 & 2160,0 & 266,1 & 1023,0 & 738,6 & $-98,0$ & 131,6 \\
MARZO & 419,3 & 1861,0 & 198,0 & 979,0 & 688,3 & $-104,5$ & 87,6 \\
ABRIL & 279,8 & 1604,0 & 128,7 & 778,9 & 562,4 & $-129,4$ & 42,1 \\
MAYO & 166,0 & 1160,0 & 73,6 & 559,3 & 302,0 & $-109,7$ & 2,3 \\
JUNIO & 101,0 & 775,0 & 44,8 & 375,8 & 189,4 & $-90,9$ & $-18,3$ \\
JULIO & 73,8 & 533,7 & 32,3 & 260,9 & 118,3 & $-123,5$ & $-26,3$ \\
AGOSTO & 78,6 & 664,7 & 33,2 & 283,7 & 177,0 & $-210,2$ & $-19,4$ \\
SEPTIEMBRE & 144,2 & 1064,0 & 61,1 & 458,5 & 334,9 & $-92,3$ & $-1,5$ \\
OCTUBRE & 267,7 & 1410,0 & 124,0 & 700,9 & 424,8 & $-78,6$ & 37,1 \\
NOVIEMBRE & 369,2 & 1727,0 & 177.5 & 870,0 & 577,5 & $-94,8$ & 66,3 \\
DICIEMBRE & 507,1 & 1996,0 & 243,7 & 996,0 & 697,4 & $-103,0$ & 109,7 \\
AÑO & 589,4 & 2126,0 & 276.9 & 1043,0 & 744,2 & $-111,1$ & 136,1 \\
\hline
\end{tabular}

Al examinar detalladamente la serie original se observa que el máximo promedio alcanzado en media hora llegó a $2160 \mu \mathrm{mol} \mathrm{s}^{-1} \mathrm{~m}^{-2}$, y ocurrió el 3 de enero entre las 12:00 h y las 12:30 h. Por su parte, el menor de estos promedios máximos llegó a solo $157,4 \mu \mathrm{mol} \mathrm{s}^{-1} \mathrm{~m}^{-2}$ y ocurrió el 3 de junio entre las 12:00 y las $12: 30 \mathrm{~h}$, hora en que el sol está a su máxima altura diaria sobre el horizonte. La tabla 3, en sus primeras dos columnas, muestra los valores medios mensuales y máximos promedios en media hora por mes.

Si se analiza la serie en función de su variación diaria, los patrones de comportamiento son bien definidos. Los máximos valores ocurren a mediodía y aumentan hacia la estación de verano, mientras que los mínimos valores son más frecuentes en horas de la noche y en invierno.

$\mathrm{Si}$ consideramos que un valor de radiación PAR superior a cero es una manifestación de luz, se puede obtener para cada día del año la cantidad de horas de luz por día a partir de esta serie de datos. El gráfico de isolíneas de radiación PAR de la figura 3 muestra la distribución diaria de esta variable a través del año. La isolínea cero marca los límites de la duración del la luz diaria y se puede obtener desde aquí el valor de las horas de luz por día, con una buena aproximación. El valor exacto de las horas de luz se obtiene de la base de datos original.

De esta forma se puede establecer que para el mes de enero el día comienza antes de las 05:00h y finaliza después de las 22 h sumando más de 17 h de luz. En invierno en cambio, la isolínea cero se ubica 


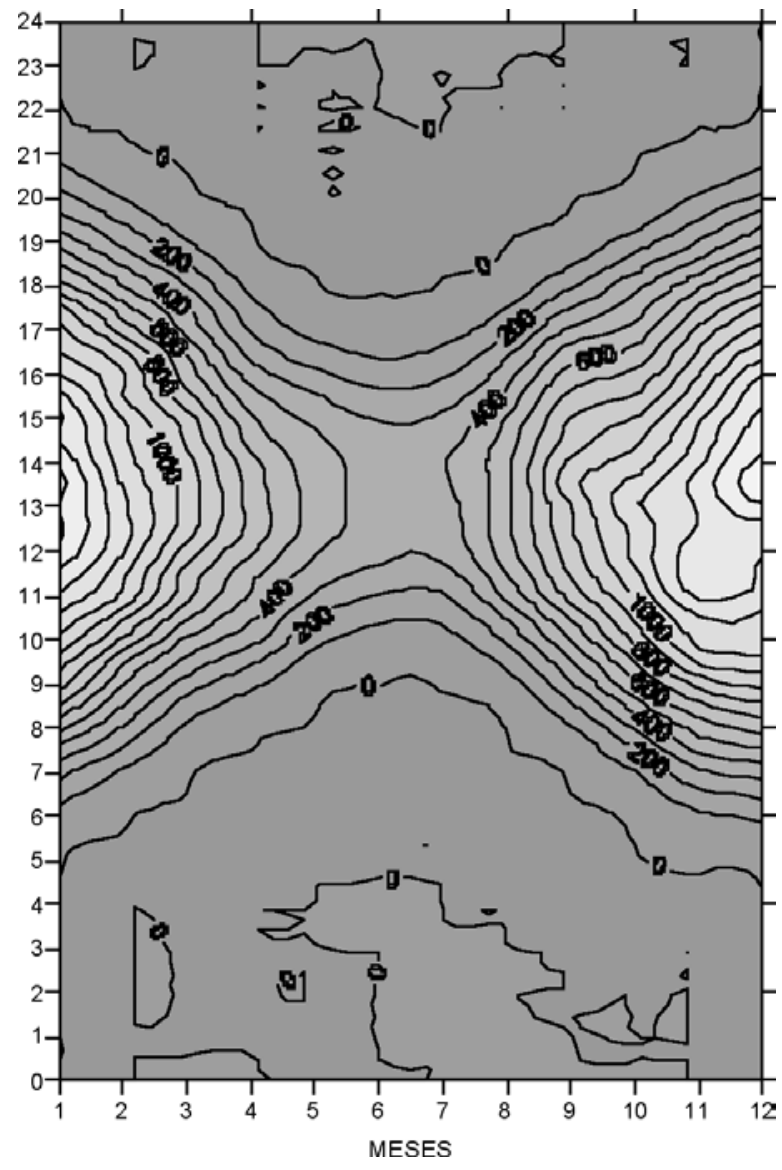

Fig. 3. Distribución diaria y anual de la radiación PAR durante el 2008.

a las 09:00h, hora en que comienza la luz solar y finaliza en la isolínea cero, ubicada alrededor de las 18:00h, completando solamente unas 9 horas de luz.

De acuerdo a lo mostrado en la figura 3 , en los meses de junio y julio, a las horas del mediodía, desaparece la isolínea de los $400 \mu \mathrm{mol} \mathrm{s}{ }^{-1} \mathrm{~m}^{-2}$. En esta figura también queda de manifiesto cómo se juntan las isolíneas hacia las horas del mediodía en las estaciones de transición, es decir, en otoño y primavera, mostrando el rápido desplazamiento de la trayectoria aparente del sol en el cielo, en estas épocas del año.

Respecto a la variación anual en promedios diarios, los máximos valores medios se obtienen a partir de noviembre, siguiendo con diciembre y enero. En estos meses los valores promedios diarios fluctúan en alrededor de unos $600 \mu \mathrm{mol} \mathrm{s} \mathrm{m}^{-2}$. Al finalizar enero los promedios diarios comienzan a

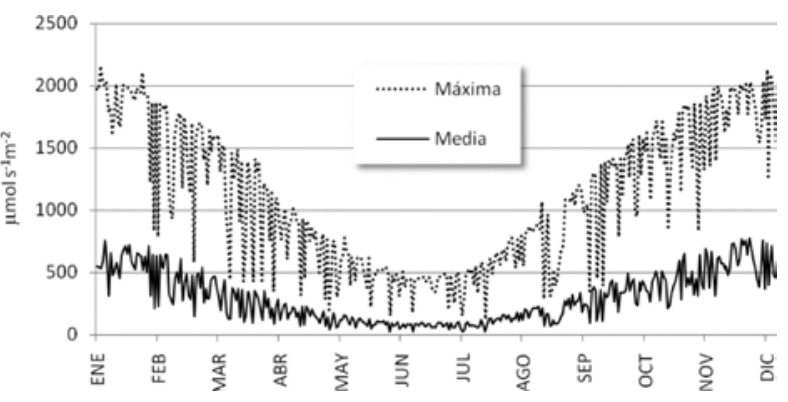

Fig. 4. Marcha diaria de la radiación PAR para el año 2008.

descender en forma paulatina hasta llegar a valores mínimos entre los meses de mayo a agosto, con promedios diarios inferiores a los $100 \mu \mathrm{mol} \mathrm{s} \mathrm{m}^{-2}$.

La figura 4 muestra la distribución de la radiación PAR a través del año en promedios diarios. La línea negra representa el valor promedio diario, en tanto que la línea de puntos representa los promedios máximos (en periodos de media hora) alcanzados en forma diaria.

Las variaciones mostradas entre un día y otro se deben a la condición de la nubosidad presente. Y si se observa los valores máximos de ambas líneas de la figura 4, los limites superiores definen, con una buena aproximación, la variación de la radiación PAR, tanto en sus valores medios como máximos diarios, en condiciones de cielo despejado, es decir, sin nubosidad.

\subsubsection{Radiación Global}

La radiación global por su parte, que incluye la radiación directa más la difusa y que cubre el rango visible e infrarrojo del espectro solar, alcanzó un valor medio anual de $155,1 \mathrm{~W} \mathrm{~m}^{-2}$, equivalente a unas $117,7 \mathrm{Kcal} / \mathrm{cm}^{2}$-año. Como ya se dijo, esta radiación contiene a la radiación PAR y de acuerdo a los valores obtenidos, esta radiación visible representa un 41,7 \% del total de la radiación global.

El mes de mayor radiación global fue enero con un valor medio de $264 \mathrm{~W} \mathrm{~m}^{-2}$, mientras que los meses de menor promedio fueron junio y julio con $32,3 \mathrm{~W} \mathrm{~m}^{-2}$ y $33,2 \mathrm{~W} \mathrm{~m}^{-2}$ respectivamente.

En relación al máximo promedio obtenido en un periodo de media hora, éste ocurrió el 18 de diciembre entre las 13:00 y las 13:30 h, alcanzando un valor de $1043,3 \mathrm{~W} \mathrm{~m}^{-2}$. Por su parte, el menor valor máximo se registró el 23 de julio entre las 


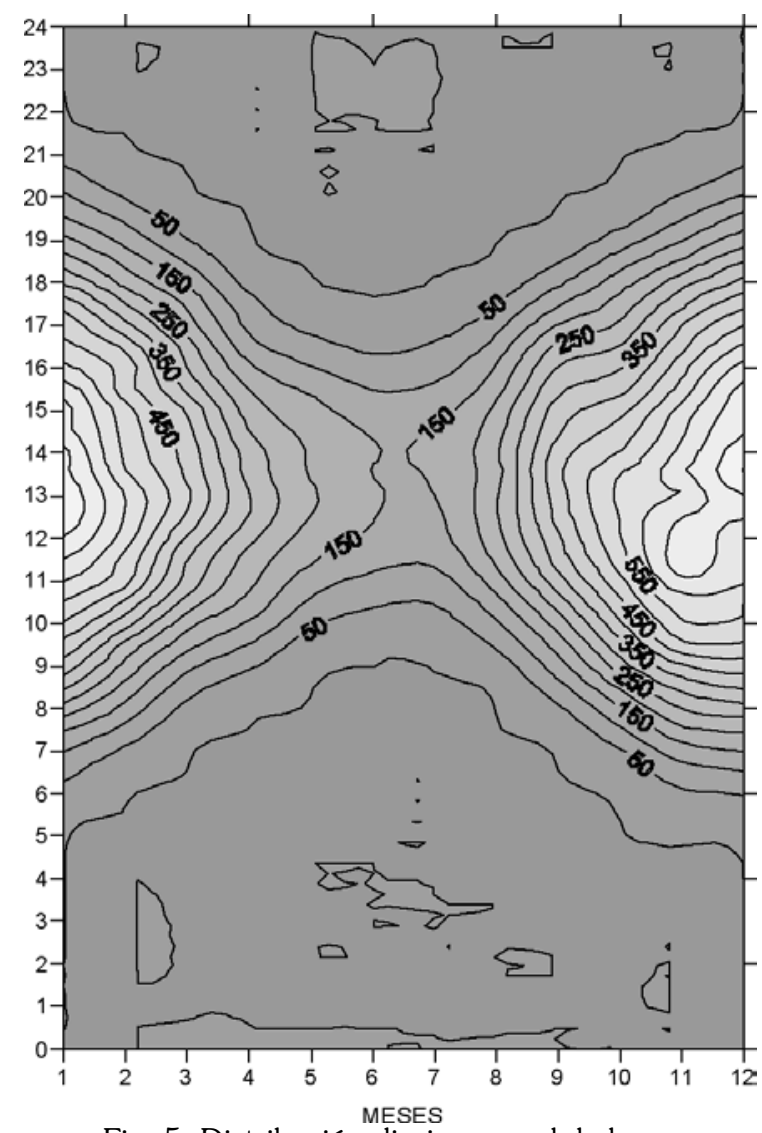

Fig. 5. Distribución diaria y anual de la radiación global durante el año 2008.

11:30 y las $12: 00$ h y llegó a sólo $46,3 \mathrm{~W} \mathrm{~m}^{-2}$. La tabla 3 , en su cuarta y quinta columna, muestra los valores medios mensuales y máximos promedios en media hora por mes.

$\mathrm{Al}$ igual que en la radiación PAR, si consideramos un valor de radiación global superior a cero es una manifestación de la energía solar, a partir de la serie de datos se puede obtener la longitud de tiempo por día en que la radiación global está presente. La figura 5 muestra a distribución de la radiación global a través del año y en su variación diaria. Aquí se puede establecer claramente la duración diaria de la radiación a partir de la isolínea cero a comienzos y final del día. De esta manera se puede establecer que en verano la radiación solar comienza a manifestarse alrededor de las 05:00h para finalizar alrededor de las $22 \mathrm{~h}$, mientras que en pleno invierno comienza a las 09:00 h y finaliza a las $18 \mathrm{~h}$ aproximadamente.

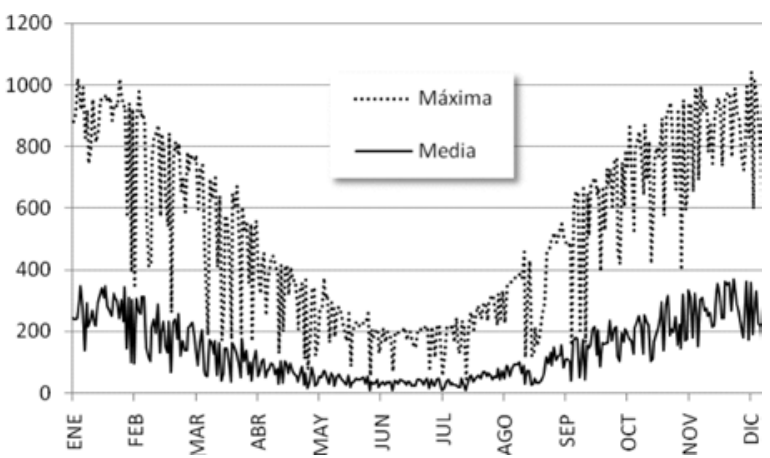

Fig. 6. Marcha diaria de la radiación global para el año 2008.

La distribución general de la radiación global es similar a la de la radiación PAR, i.e., los máximos valores se producen a mediodía y en verano, mientras que los promedios mínimos ocurren en la noche y en invierno. Enero es el mes que presenta los mayores promedios y ocurren entre las $12 \mathrm{y}$ las 14 horas.

Con respecto a la variación anual en función de los promedios diarios, los máximos valores ocurrieron a partir de noviembre, seguido de diciembre, enero y febrero con promedios de alrededor de unos $300 \mathrm{~W} \mathrm{~m}^{-2}$. Por su parte, los promedios diarios mínimos ocurrieron durante los meses de mayo, junio y julio, con valores que no superaron a los $60 \mathrm{~W} \mathrm{~m}^{-2}$.

La figura 6 muestra la marcha anual de la radiación global diaria. La línea negra muestra el promedio diario obtenido, mientras que la línea de puntos muestra los promedios máximos (en media hora) ocurridos diariamente.

$\mathrm{Al}$ igual que la radiación $\mathrm{PAR}$ las variaciones entre días cercanos están motivadas por la nubosidad presente al momento de la adquisición del dato promedio. En la figura 6 se puede apreciar que el límite superior de los valores máximos diarios define en forma bastante clara los valores de la radiación global en condiciones de cielo despejado, sin la intervención de nubes.

De manera general se puede decir que en el caso de la radiación PAR y la radiación global, los valores mínimos, i.e., los obtenidos en pleno invierno, son positivos, o sea, siempre hay aporte de energía solar durante el día. 


\subsubsection{Radiación Neta}

La radiación neta, que involucra un mayor rango espectral y además varios componentes de la radiación (radiación reflejada por la superficie, irradiación de la superficie, radiación difusa, radiación directa) y que en definitiva expresa un balance entre la energía solar que recibe la superficie terrestre y la que sale de ella por reflexión y emisión, alcanzó un promedio de $45,6 \mathrm{~W} \mathrm{~m}^{-2}$, con máximos mensuales en enero y diciembre, alcanzando promedios sobre los $160 \mathrm{Wm}^{-2}$.

El mes que presentó el menor promedio fue junio con un balance negativo que llegó a los $-26,4$ $\mathrm{W} \mathrm{m}^{-2}$. En general los meses de mayo a agosto presentaron un balance negativo de energía, es decir, de la superficie terrestre salió más energía que la que entró por causa del sol.

La tabla 3 en sus tres últimas columnas, muestra los valores máximos, mínimos y medios de

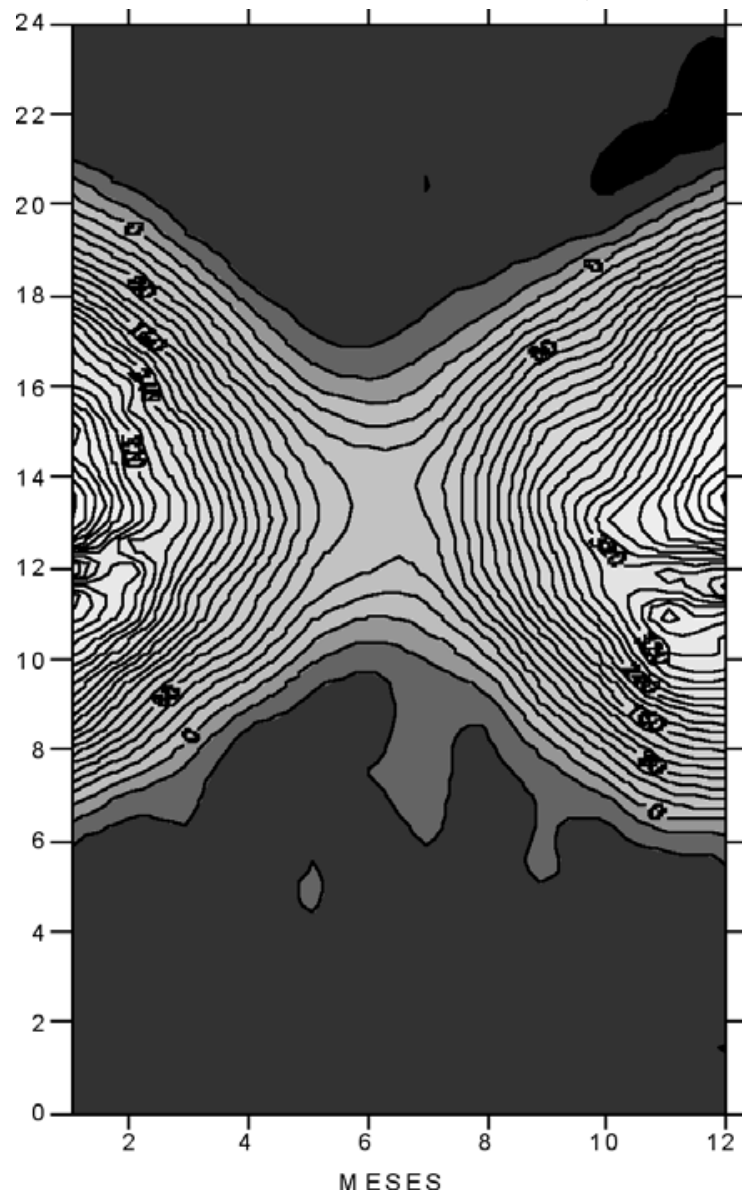

Fig. 7. Isolíneas de radiación neta durante el año 2008. la radiación neta para cada mes y para el año 2008. Respecto a la distribución anual de esta energía y en su variación diaria, ésta sigue el mismo patrón de las radiaciones ya analizadas, presentando máximos promedios en horas del mediodía y en verano, mientras que los valores mínimos se presentan en horas de la noche y en invierno.

La figura 7 muestra la distribución de la radiación neta a través del año 2008 y su comportamiento a través del día. En esta figura la isolínea cero muestra el momento de un balance nulo, es decir un instante en que la energía de entrada y salida están equilibradas. Así, se puede establecer que en verano se comienza a ganar energía solar a partir de las 8:15 h aproximadamente y se deja de recibir alrededor de las 20:00 horas. En invierno, esta isolínea marca un punto de partida a las 11:00 horas y finaliza cerca de las 16:30 horas. Las áreas oscuras del gráfico muestran los valores negativos de energía, es decir la energía que sale de la superficie terrestre.

En la figura 7 se puede observar que si bien, la radiación es mayor tanto a mediodía como en los meses de verano, aparecen unos núcleos de isolíneas en los meses de noviembre, diciembre, enero y febrero a horas de mediodía, los cuales desordenan un tanto la distribución de aquellas. Esto deja en evidencia una variación provocada por una causa ajena al comportamiento de esta variable y puede deberse a alguna sombra proyectada sobre el sensor en estos meses a horas del mediodía.

Los valores medios en este balance energético oscilan en torno a los $150 \mathrm{~W} \mathrm{~m}^{-2}$ en verano, mientras que en invierno el promedio es negativo. Aunque ya en marzo aparecen los primeros balances negativos de energía, es en abril que se hacen más frecuentes y, desde el 2 de mayo los promedios diarios muestran un flujo negativo de energía, el que dura hasta el 20 de agosto; corresponde a la línea llena del gráfico de la figura 9. Los valores medios diarios mínimos oscilan entre $-20 \mathrm{~W} \mathrm{~m}^{-2}$ y $-40 \mathrm{~W}$ $\mathrm{m}^{-2}$. La línea de puntos de esta figura muestra los promedios máximos alcanzados en media hora para cada día del 2008, mientras que la línea segmentada muestra los valores medios mínimos alcanzados en madia hora en cada día del año 2008.

$\mathrm{Al}$ igual que en el caso de la radiación PAR y la radiación global esta radiación está afectada en forma importante por la nubosidad presente al momento 


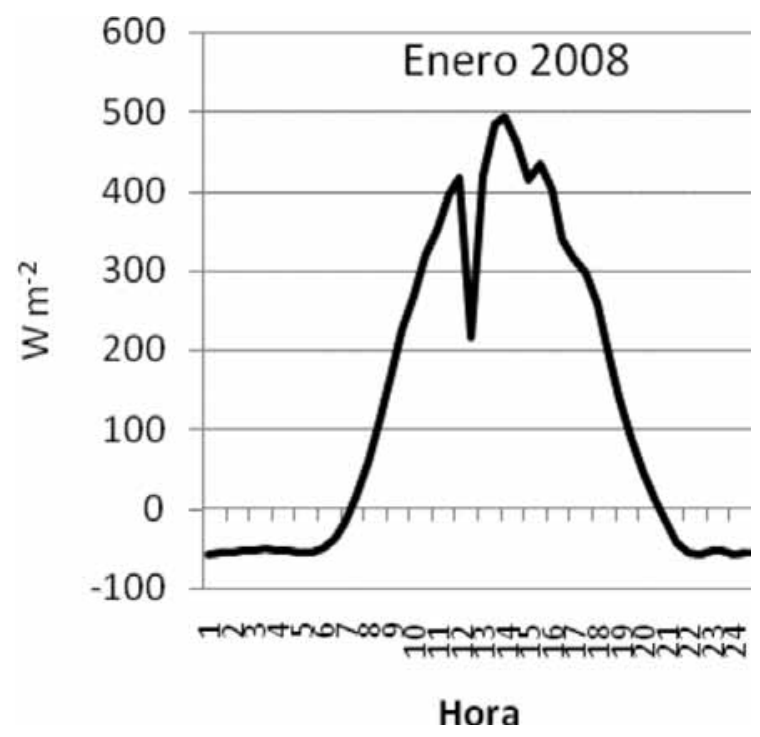

Fig. 8. Radiación neta mensual para enero, mostrando un error sistemático en los datos producto de una sombra proyectada sobre el sensor a mediodía, situación similar a la de los meses de noviembre, diciembre y febrero.

de la medición, disminuyendo considerablemente sus valores. De esta forma, es posible aproximar el comportamiento a condiciones ideales tomando los límites superiores de las curvas de valores medios y máximos para estimar la energía en condiciones de cielo despejado.

Por último, cabe mencionar que la energía negativa o energía saliente de la superficie terrestre,

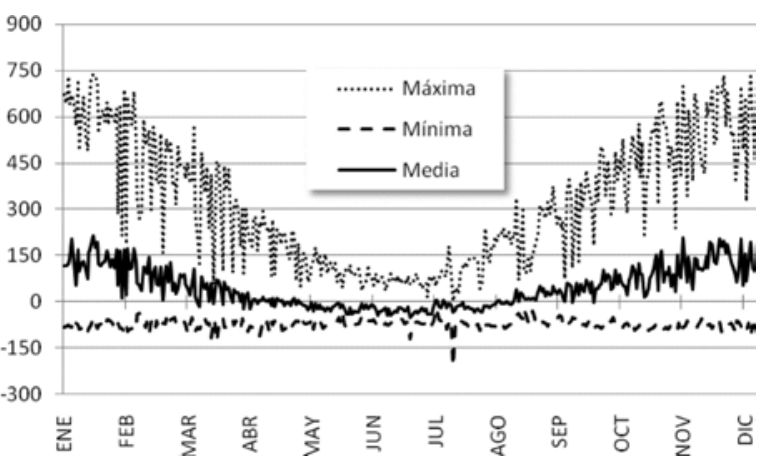

Fig. 9. Marcha diaria de la radiación neta para el año 2008.

manifestada en horas de la noche y madrugada especialmente, se comporta más o menos constante durante todo el año y la variación sistemática y estacional lo presenta el flujo de energía positiva o entrante.

\subsection{Temperaturas}

La temperatura media del aire en Posesión y para el año 2008 alcanzó a los $7,3^{\circ} \mathrm{C}$, unos $0,4^{\circ}$ $\mathrm{C}$ sobre el promedio alcanzado en Punta Arenas (Butorovic 2008). Cabe destacar que la temperatura del año 2008 en la ciudad, alcanzó un promedio superior al normal en $0,4^{\circ} \mathrm{C}$, por lo que se puede inferir que, en la localidad de Posesión también el promedio alcanzado es superior al normal.

TABLA 4. Temperatura media y extremas mensuales del aire en Posesión

\begin{tabular}{|c|c|c|c|c|c|c|c|c|c|c|c|c|c|}
\hline & $\mathrm{NE}$ & EB & & & & V & $\mathrm{L}$ & & & T & & DIC & $A \tilde{n}$ \\
\hline & {$[\mathbf{T}$} & 128 & & & & & 1,9 & & & & & $2, L$ & \\
\hline & 25,3 & 3,7 & 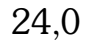 & ,2 & 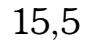 & 9,2 & + & 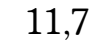 & 7,7 & 18,2 & 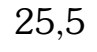 & אל & 20, \\
\hline Minimim &, 4 & 5,4 & 4,3 & $-0,8$ & $-8,2$ & $-7,9$ & $-6,2$ & $-9,4$ & $-4,3$ & $-2,2$ & $-3,2$ & 3,3 & S, \\
\hline
\end{tabular}

El mes de mayor promedio para el 2008 fue febrero con un valor de $12,8^{\circ} \mathrm{C}$, seguido de enero con $12,4^{\circ} \mathrm{C}$, diciembre con $12,2^{\circ} \mathrm{C}$ y marzo con $11,3^{\circ} \mathrm{C}$ sumando cuatro meses con promedio sobre $10^{\circ} \mathrm{C}$, característico de las localidades de esta área de la Patagonia (Pisano 1977). Por su parte, el más frío fue agosto con $1,4^{\circ} \mathrm{C}$, seguido de julio con un promedio de $1,9^{\circ} \mathrm{C}$. Por su parte, las extremas máximas llegaron a los $25,5^{\circ} \mathrm{C}$ en noviembre y a los $25,3^{\circ} \mathrm{C}$ en enero. Otras temperaturas altas de importancia se registraron en diciembre, marzo y febrero con valores de $24,9^{\circ} \mathrm{C}, 24,0^{\circ} \mathrm{C}$ y $23,7^{\circ}$ $\mathrm{C}$ respectivamente. Las mínimas bajo cero, que comenzaron a partir de abril y duraron hasta no- 
viembre, llegaron a su extremo negativo en el mes de agosto, bajando hasta los $-9,4^{\circ} \mathrm{C}$. La tabla 4 muestra los valores medios y extremos alcanzados por la temperatura del aire en Posesión, durante 2008.

Se puede observar así, que los valores medios más altos se alcanzaron en los meses de enero y febrero entre las 13 y las 17 horas, con promedios de alrededor de $16^{\circ} \mathrm{C}$, mientras que en los meses de julio y agosto los promedios máximos durante el día, apenas superaron los $3^{\circ} \mathrm{C}$ y llegando a valores medios de $1^{\circ} \mathrm{C}$ y $0^{\circ} \mathrm{C}$ durante la noche y madrugada. La figura 10 muestra la distribución de la temperatura en forma diaria y por mes.

A nivel de promedios diarios, el máximo valor se registró el 27 de febrero y alcanzó un valor medio diario de $17,5^{\circ} \mathrm{C}$. Otros valores importantes y sobre $17^{\circ} \mathrm{C}$ se registraron los días 30 de enero y 26 de noviembre.

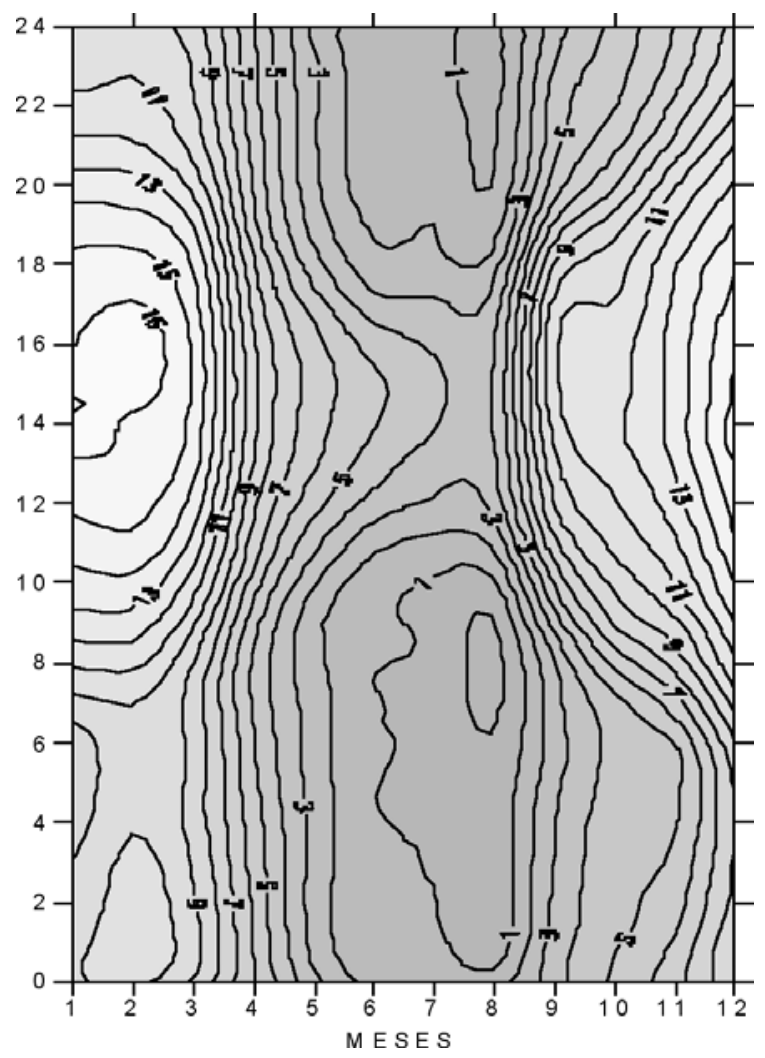

Fig. 10. Isotermas de la temperatura del aire.

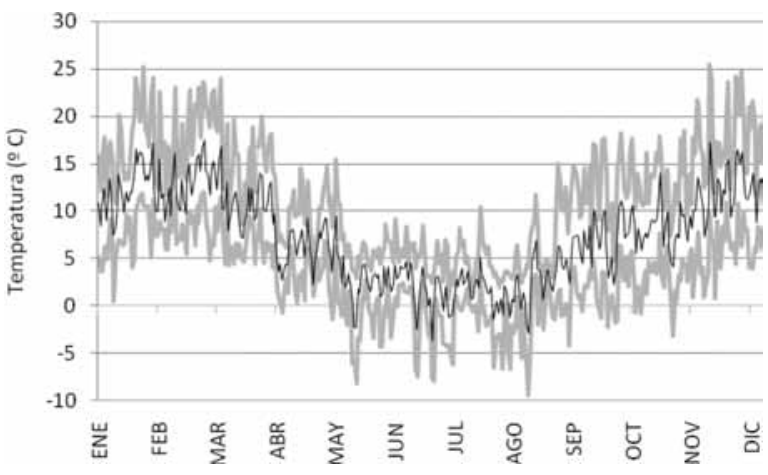

Fig. 11. Marcha diaria de la temperatura durante el año 2008.

Durante los meses de junio, julio y agosto, fue frecuente que los promedios diarios alcanzaran valores negativos, con mínimas inferiores a $-5^{\circ} \mathrm{C}$, aunque las máximas instantáneas estuvieron sobre los $10^{\circ} \mathrm{C}$ durante el día. En los meses de verano, los promedios diarios fluctúan entre los $10^{\circ} \mathrm{C}$ y los $15^{\circ} \mathrm{C}$, valores que también se presentan en forma frecuente durante los meses de noviembre a abril. La figura 11 muestra el desarrollo de la temperatura media diaria (línea negra) y los extremos máximos y mínimos (líneas grises) alcanzados en forma diaria a través del 2008.

Al examinar la figura 11 se deduce que en esta localidad no existen periodos prolongados con temperatura bajo cero y más bien se puede ver que son continuas las condiciones de hielo y deshielo a nivel diario, por lo que se puede suponer que una capa de nieve en esta zona es poco duradera.

3.3 Temperatura del suelo

Las mediciones obtenidas a $30 \mathrm{~cm}$ de profundidad en esta localidad, muestran para el año 2008 una temperatura media de $8,2^{\circ} \mathrm{C}$, alcanzándose un promedio máximo mensual de $15,4^{\circ} \mathrm{C}$ en diciembre y un valor medio mensual mínimo de $0,7^{\circ} \mathrm{C}$ en julio. Por su parte el máximo valor obtenido para un periodo de media hora, llegó a los $18,5^{\circ} \mathrm{C}$ en el 26 de enero entre las 1:30 h y las $2: 30 \mathrm{~h}$, mientras que el promedio mínimo fue de $-0,1^{\circ} \mathrm{C}$ y ocurrió el 10 de julio entre las 22:00 h y las 22:30 h. 
TABLA 5. Temperatura media y extremas mensuales del suelo $(30 \mathrm{~cm})$ en Posesión

\begin{tabular}{cccccccccccccc}
\hline & ENE & FEB & MAR & ABR & MAY & JUN & JUL & AGO & SEP & OCT & NOV & DIC & Año \\
\hline Media & 15,1 & 15,1 & 12,8 & 7,7 & 3,8 & 1,8 & 0,7 & 0,8 & 5,0 & 8,5 & 11,2 & 15,4 & 8,2 \\
Máx. & 18,5 & 18,2 & 16,8 & 12,2 & 7,0 & 2,9 & 2,1 & 2,7 & 9,0 & 10,9 & 15,3 & 17,6 & 18,5 \\
Mín. & 12,3 & 13,5 & 10,0 & 5,4 & 1,6 & 0,4 & $-0,1$ & 0,1 & 1,8 & 5,0 & 8,3 & 12,5 & $-0,1$ \\
\hline
\end{tabular}

La tabla 5 muestra los valores medios mensuales y los extremos alcanzados durante el año 2008. Los valores extremos para cada mes corresponden a los obtenidos en un periodo de media hora.

A nivel de promedios diarios la variación es claramente estacional y muy correlacionada con las variaciones del la radiación solar. Mientras la temperatura media diaria oscila en torno a los $15^{\circ}$ $\mathrm{C}$ durante los meses de verano, en invierno este valor queda muy cerca de los $0^{\circ} \mathrm{C}$. La figura 12 muestra la variación de la temperatura media diaria del suelo. La línea negra muestra el promedio diario, mientras que las líneas grises muestran los extremos alcanzados en cada día del 2008. Aquí se aprecia claramente la escasa amplitud térmica que se alcanza diariamente y que contrasta con el comportamiento de la temperatura del aire mostrado en la figura 11.

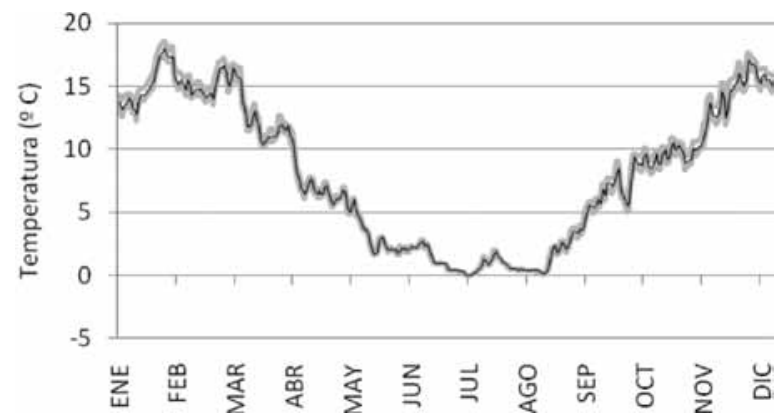

Fig. 12. Distribución de la temperatura del suelo media diaria.

A partir de fines de marzo y hasta fines de mayo la temperatura del suelo comienza a bajar en forma paulatina y rápida, y los promedios diarios descienden desde unos $15^{\circ} \mathrm{C}$ hasta unos $2^{\circ} \mathrm{C}$. Igual cosa ocurre entre fines de agosto y noviembre, pero en sentido contrario, es decir, la temperatura del suelo va en aumento rápido y sostenido hasta alcanzar alrededor de unos $15^{\circ} \mathrm{C}$.

La variación diaria de la temperatura del suelo es prácticamente nula, es decir no se detecta una diferencia entre la temperatura a mediodía con la temperatura de la noche o la madrugada. En este aspecto el comportamiento térmico diario del suelo difiere del de la temperatura diaria del aire, la cual sí se manifiesta en patrones similares a la variación diaria de la radiación solar.

A excepción de enero, que muestra un leve aumento de la temperatura hacia el mediodía, el resto de los meses muestra un comportamiento constante de la temperatura a lo largo del día, alcanzándose valores mensuales para lo días de verano en la isolínea $14^{\circ} \mathrm{C}$, mientras que en invierno la isolínea que representa el comportamiento diario mensual es de $1^{\circ} \mathrm{C}$.

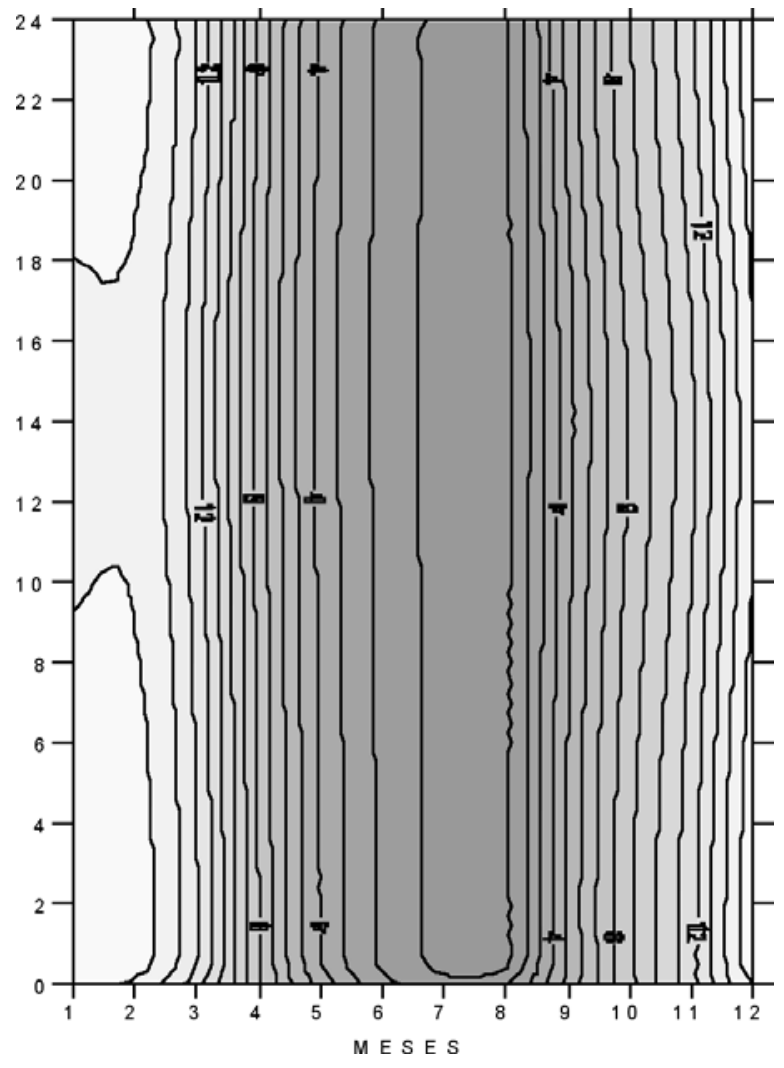

Fig. 13. Diagrama de isotermas diaria y mensual del suelo. 
La variación sistemática de la radiación solar a través del año, sí afecta a la variación de la temperatura del suelo y en la figura 14 queda de manifiesto, debido a los altos valores registrados en verano y en contraste con los bajos promedios registrados en invierno.

La figura 13 muestra la variación diaria de la temperatura del suelo y su distribución mensual para el año 2008.

La temperatura media anual del suelo fue $0,9^{\circ}$ $\mathrm{C}$ superior a la del aire. Sin embargo, las mayores diferencias ocurren durante los meses de verano, superando la temperatura del suelo a la del aire, en tanto que las menores diferencias se producen en invierno, siendo mayor la temperatura del aire. Así, diciembre alcanzó una temperatura del suelo superior en $3,2^{\circ} \mathrm{C}$ al promedio alcanzado en el aire. Esta diferencia se hizo mínima durante los meses de mayo y junio, con un valor de $0,1^{\circ} \mathrm{C}$ y $0,3^{\circ} \mathrm{C}$ respectivamente.

El análisis de los promedios mensuales muestra que la temperatura del suelo presenta una mayor amplitud térmica que la obtenida en el aire. En efecto, mientras en el suelo esta amplitud llega a los $14,7^{\circ} \mathrm{C}$, en el aire llega a los $11^{\circ} \mathrm{C}$. Por otra parte, en este comportamiento es posible observar que, mientras la temperatura del suelo supera a la del aire durante los meses de verano, en invierno esta situación se invierte y es la temperatura del aire la que supera a la del suelo, situación que ocurre durante los meses de mayo, junio, julio y agosto. La figura 13 muestra las temperaturas medias mensuales del aire y del suelo en Posesión, durante el año 2008.

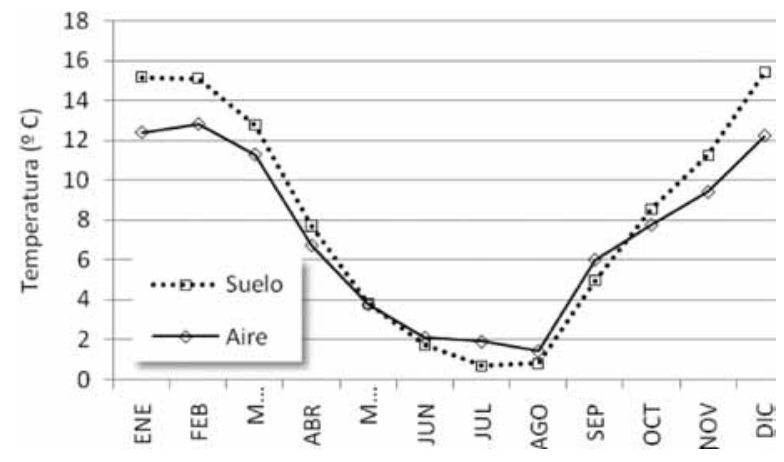

Fig. 14. Temperaturas medias mensuales del aire y del suelo durante el año 2008.

Esta diferencia de comportamiento entre el aire y el suelo se manifiesta de otra manera cuando se analizan los valores extremos alcanzados en cada mes, en periodos de media hora. Si se calcula la amplitud térmica absoluta para cada mes, es decir, el máximo valor obtenido en media hora, menos el mínimo valor mensual obtenido para el mismo periodo, se obtiene la amplitud absoluta para el mes. De esta manera, mientras en el aire se obtienen amplitudes máximas por sobre los $20^{\circ} \mathrm{C}$, en el suelo estos valores solo llegan a los $4,5^{\circ} \mathrm{C}$. La tabla 6 muestra los valores de las amplitudes absolutas alcanzadas en cada mes del año 2008 para la localidad de Posesión.

TABLA 6. Amplitud térmica absoluta mensual del aire y del suelo

\begin{tabular}{crrrrrrrrrrrr}
\hline & ENE & FEB & MAR & AGR & MAY & JUN & JUL & AGO & SEP & OCT & NOV & DIC \\
\hline Suelo & 3.4 & 3.1 & 4.0 & 4.5 & 3.2 & 1.1 & 1.4 & 2.0 & 4.1 & 2.4 & 4.0 & 2.2 \\
Aire & 24.8 & 18.3 & 19.7 & 19.0 & 23.7 & 17.1 & 16.6 & 21.2 & 22.0 & 20.4 & 28.7 & 21.6 \\
\hline
\end{tabular}

De manera general se puede establecer que la temperatura del aire, al ser un medio que absorbe y transmite en forma eficaz la energía solar, sigue los mismos patrones de variación de ésta, mientras que el suelo, un medio de gran absorción de la energía del sol, pero de transmisión casi nula de esta energía, solamente sigue el patrón estacional de la variación, anulando casi por completo la variación diaria de la temperatura.

\subsection{Precipitación}

El monto anual de precipitaciones en Posesión para el año 2008 alcanzó a los 274,1 mm (1 m²). Este monto se acumuló en un total de 146 días que presentaron precipitaciones, equivalentes al $40 \%$ de los días del año. Dicho de otro modo, el $40 \%$ de los días presentó precipitaciones en algún momento del día. En general se puede decir que las precipitaciones son numerosas y de corta duración a través de todo 
el año. No se observa una estacionalidad clara en el comportamiento pluviométrico y todos los meses presentan numerosos días con precipitación, aunque de variados montos.

El mes más lluvioso del 2008 fue marzo que acumuló $52 \mathrm{~mm}$, mientras que el mes más seco fue septiembre con solo $4,7 \mathrm{~mm}$. Otros montos pequeños lo registraron los meses de diciembre, enero y octubre con totales inferiores a $10 \mathrm{~mm}$.
La máxima precipitación diaria alcanzó a los $22,7 \mathrm{~mm}$ y se registró el 28 de noviembre, mes en que el total llegó a los $35,2 \mathrm{~mm}$, representando por tanto esta precipitación al $62,7 \%$ del total mensual. La tabla 7 muestra los montos diarios alcanzados por la precipitación, la suma mensual para cada uno de ellos, la máxima precipitación alcanzada en 24 horas y el número de días que presentaron algún monto de precipitación.

TABLA 7. Precipitación diaria durante el año 2008 en Posesión.

\begin{tabular}{ccccccccccccc}
\hline Día & ENE & FEB & MAR & ABR & MAY & JUN & JUL & AGO & SEP & OCT & NOV & DIC \\
\hline 1 & 0,2 & - & - & 0,2 & - & - & - & - & 2,0 & 0,3 & - & - \\
2 & 1,6 & 1,4 & - & - & - & 0,1 & - & - & - & 0,5 & - & - \\
3 & - & 0,1 & - & 0,6 & 0,2 & 2,6 & - & 4,9 & - & 0,4 & - & - \\
4 & - & - & 0,1 & - & - & 0,1 & - & 0,2 & - & 0,6 & - & 0,1 \\
5 & - & - & 0,2 & 0,1 & - & - & - & 1,0 & - & 2,2 & - & - \\
6 & 1,1 & - & - & 2,4 & - & - & - & 1,0 & 1,2 & - & 2,3 & - \\
7 & 2,3 & - & 1,4 & - & 0,1 & 0,1 & 0,3 & - & - & - & 0,1 & - \\
8 & 0,9 & 3,2 & 12,6 & - & - & - & - & - & - & - & - & - \\
9 & - & 8,8 & - & - & 0,2 & 0,3 & - & - & - & - & - & - \\
10 & 0,4 & 8,9 & 0,4 & 1,6 & - & 1,7 & 1,3 & - & 0,8 & 1,9 & - & - \\
11 & 0,2 & - & 2,0 & 0,8 & - & 0,2 & 0,3 & - & - & 1,9 & 0,2 & - \\
12 & - & - & - & - & 0,6 & 2,5 & 2,0 & - & - & 0,2 & 0,7 & - \\
13 & 1,1 & 1,7 & - & - & - & 1,3 & - & - & - & - & - & - \\
14 & - & - & - & - & 0,2 & 0,4 & - & - & - & - & - & - \\
15 & 0,2 & 1,5 & 0,5 & - & - & 5,0 & - & - & - & - & 4,8 & 2,1 \\
16 & - & - & 1,0 & 3,5 & 0,5 & - & 0,2 & - & - & 0,3 & 3,7 & - \\
17 & - & 0,1 & 0,2 & 4,5 & 0,6 & - & - & - & - & - & - & - \\
18 & 0,1 & - & 10,7 & - & - & - & 0,1 & - & - & - & - & - \\
19 & - & 0,9 & 18,6 & 0,6 & - & - & 1,8 & - & - & - & - & - \\
20 & - & - & 2,3 & 1,4 & - & - & 11,6 & - & - & - & 0,3 & - \\
21 & - & 0,2 & 0,1 & - & 0,6 & 0,2 & 1,3 & 0,1 & 0,1 & - & - & 0,1 \\
22 & - & - & - & - & 1,8 & - & 1,1 & 3,1 & 0,5 & - & 0,1 & 0,7 \\
23 & - & - & 1,2 & - & 11,5 & - & 8,5 & - & 0,1 & 1,2 & 0,4 & 0,2 \\
24 & - & 0,1 & - & - & 0,5 & - & 0,1 & - & - & - & - & 0,7 \\
25 & - & - & - & - & 7,4 & - & - & - & - & - & - & - \\
26 & - & 0,1 & - & 6,8 & 0,8 & - & - & 0,1 & - & - & - & 0,5 \\
27 & - & - & 0,2 & 0,2 & - & 0,1 & - & 0,5 & - & - & 0,2 & 1,5 \\
28 & - & - & - & 1,5 & - & 0,5 & - & 0,1 & - & - & 22,7 & \\
29 & - & 2,1 & - & - & - & - & - & 4,6 & - & - & 0,7 & 1,9 \\
30 & 0,3 & & 0,5 & 3,6 & - & - & - & 8,8 & - & - & - & 0,1 \\
31 & 0,6 & & - & & - & & 0,1 & 4,3 & & 0,4 & & - \\
\hline Suma & 9,0 & 29,1 & 52,0 & 27,8 & 25,0 & 15,1 & 28,7 & 28,7 & 4,7 & 9,9 & 36,2 & 7,9 \\
\hline Max 24 h & 2,3 & 8,9 & 18,6 & 6,8 & 11,5 & 5,0 & 11,6 & 8,8 & 2,0 & 2,2 & 22,7 & 2,1 \\
\hline$N^{\circ}$ días & 12 & 13 & 16 & 14 & 13 & 14 & 13 & 12 & 6 & 11 & 12 & 10 \\
\hline & & & & & & & & & & & &
\end{tabular}

Con respecto a los antecedentes históricos de precipitación, mostrado en la tabla 1 , al comienzo de este trabajo, el monto anual alcanzado durante el 2008 fue inferior en $27 \mathrm{~mm}$, siendo los meses de marzo y noviembre los que superaron por más de $10 \mathrm{~mm}$ a los promedios históricos y enero y diciembre los que estuvieron muy por debajo de estos promedios.

La estación toma muestras de las variable cada media hora y en el caso de las precipitaciones representa un valor acumulado de lluvia durante este lapso de tiempo, de manera que se registra un 
detalle muy interesante, ya que a diferencia de los registros tradicionales (diarios) aquí es posible estimar la velocidad de la lluvia a partir de los registros acumulados.

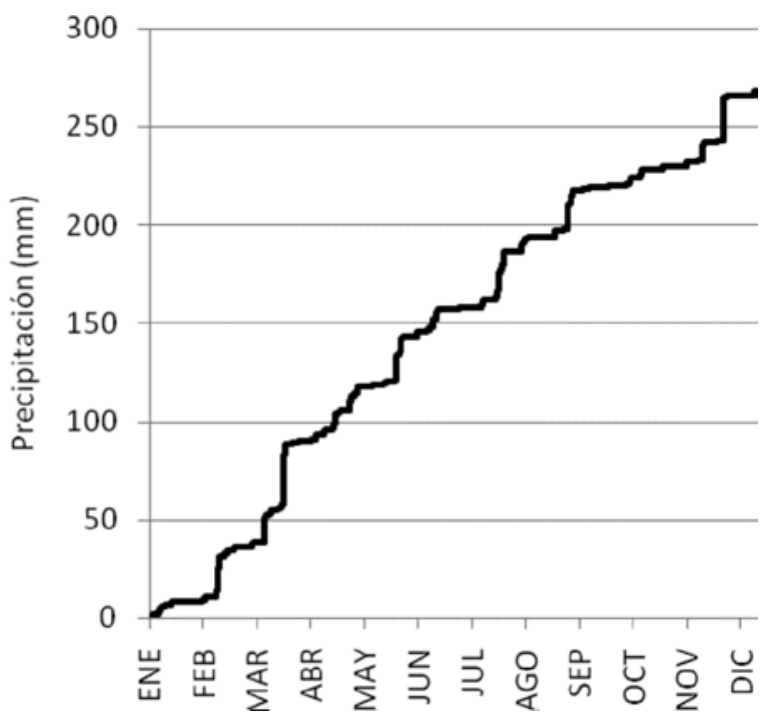

Fig. 15. Acumulación de las precipitaciones durante el año 2008.
La figura 15 muestra la acumulación de las precipitaciones a través del año 2008 y las variadas pendientes de la curva indican la velocidad de la lluvia, entendiéndose con esto, la cantidad de precipitación por unidad de tiempo en cada evento de precipitación. De esta manera se puede apreciar en el grafico que las mayores velocidades se presentaron en los meses de marzo, julio y noviembre, siendo esta última la de máxima velocidad de lluvia y ocurrió finalizando el día 27 y a comienzos del 28 , ocasión en que durante 5 horas la precipitación acumuló unos $22,9 \mathrm{~mm}$, lo que da para este tiempo una velocidad media de unos 4,6 $\mathrm{mm} \mathrm{h}^{-1}$. Otras lluvias presentaron velocidades similares, pero montos mucho menores, debido a su corta duración.

\subsection{Presión atmosférica}

La presión atmosférica, presenta diferencias menores a otras variables atmosféricas, entre localidades distantes de Magallanes, de manera que los valores de presión obtenidos en Posesión no difieren mayormente de los obtenidos en Punta Arenas y las diferencias existentes entre estas localidades se deben principalmente a la diferencia de altitud de las estaciones.

TABLA 8. Presión atmosférica medias y extremas mensuales en Posesión

\begin{tabular}{|c|c|c|c|c|c|c|c|c|c|c|c|c|c|}
\hline & ENE & FEB & MAR & ABR & MAY & JUN & JUL & AGO & SEP & OCT & NOV & DIC & Año \\
\hline Media & 999,3 & 999 & 1002,4 & 994, & 1001,2 & 999,9 & 998,9 & 997,4 & 1007,7 & 997,7 & 994,2 & 999,9 & 999,4 \\
\hline Max & 1017,0 & 1015 & 1014, & 1011 & 1019,0 & 1020,0 & 1023,0 & 1020,0 & 1025,0 & 1019,0 & 1019,0 & 1023 & 1025,0 \\
\hline Min & 977,0 & 983,0 & 983,0 & 969,0 & 987,0 & 974,0 & 971,0 & 978,0 & 990,0 & 977,0 & 969,0 & 976,0 & 969,0 \\
\hline
\end{tabular}

La región de Magallanes se ubica en una zona de la circulación general de la atmósfera tal que en algún momento del año la masa de aire que predomina proviene de latitudes subtropicales y en otra época la masa que predomina es de origen antártico. De manera general se puede decir que, durante el año, Magallanes se encuentra ubicado en una zona de encuentro entre estas dos grandes masas de aire y las variaciones de la presión obedecen a la predominancia que tengan éstas en algún momento. Durante el 2008 la presión atmosférica, a nivel de la estación de Posesión, alcanzó un promedio de 999,4 hPa. El mes de mayor promedio fue septiembre con un valor de $1007,7 \mathrm{hPa}$, mientras que el mes de menor promedio de presión fue noviembre con $994,2 \mathrm{hPa}$, seguido de abril con $991,5 \mathrm{hPa}$. El valor máximo en un periodo de media hora llegó a los 1025 hPa y ocurrió en noviembre, mientras que 
promedio mínimo fue de $969 \mathrm{hPa}$ y ocurrieron en abril y en noviembre. La tabla 8 muestra los valores medios mensuales de la presión atmosférica, así como los extremos alcanzados en cada mes, mientras que la figura 16 muestra la distribución promedio diario por cada mes.

La variación diaria promedio de la presión durante cada mes, prácticamente no existe, es decir, no se evidencia una dependencia de las variaciones diarias de la radiación solar. A nivel promedios mensuales, se observan periodos de alta presión durante los meses de marzo y septiembre, meses que corresponden a las estaciones transicionales $y$ donde la zona de encuentro entre masa subtropicales y antárticas (frente polar) esta posada sobre Magallanes, evidentemente con una dinámica que provoca variaciones de este comportamiento entre un año y otro.

\subsection{Humedad relativa}

Esta variable presentó un promedio anual del $70,6 \%$. El mes de mayor humedad fue junio con un valor de $84 \%$, en tanto que el de menor promedio fue noviembre con un $59,9 \%$.

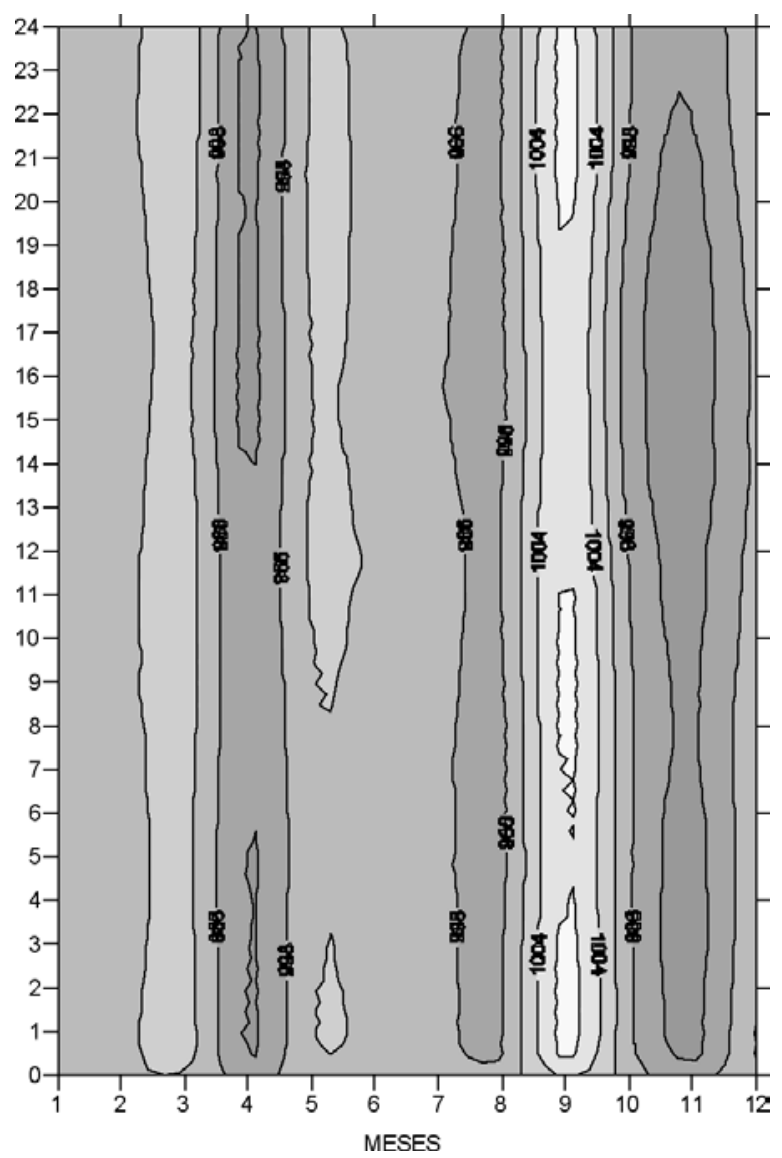

Fig. 16. Diagrama de isobaras diaria y mensual.

TABLA 9. Humedad relativa media y extremas mensuales en Posesión.

\begin{tabular}{cccccccccccccc}
\hline & ENE & FEB & MAR & ABR & MAY & JUN & JUL & AGO & SEP & OCT & NOV & DIC & AÑO \\
\hline Media & 61.9 & 65.2 & 70.6 & 72.1 & 75.8 & 84.0 & 81.4 & 79.4 & 72.1 & 63.4 & 59.9 & 60.8 & 70.6 \\
Max & 99.2 & 96.8 & 98.5 & 95.5 & 95.1 & 99.1 & 99.1 & 98.7 & 98.9 & 97.8 & 96.0 & 94.6 & 99.2 \\
Min & 12.3 & 26.6 & 27.2 & 32.1 & 34.4 & 49.9 & 35.3 & 35.7 & 22.8 & 18.1 & 19.2 & 19.4 & 12.3 \\
\hline
\end{tabular}

Por su parte, el máximo promedio en media hora llegó al 99,1 \% en junio y julio, mientras que el menor promedio en media hora llegó al 12,3 \% en enero, La tabla 9 muestra los valores medios y extremos mensuales para el 2008 en Posesión

Al igual que la temperatura y como una dependencia de ésta, la humedad relativa del aire muestra variaciones similares, a lo largo del día y a través del año. En esta dependencia, la humedad relativa se aleja del punto de saturación cuando la temperatura sube y viceversa, obteniéndose los valores más bajos a horas del mediodía y en verano y los más altos en horas de la noche y en invierno.

El diagrama de la figura 17 muestra la distribución de la humedad relativa del aire a través del día y en forma mensual. Aquí se observa claramente que mientras en las horas de mediodía de verano se rodea por una isolínea de $50 \%$, en invierno la isolínea es de $75 \%$. Igualmente mientras en la noche y madrugada las isolíneas máximas de verano alcanzan hasta el $75 \%$, en invierno llegan al $85 \%$. 


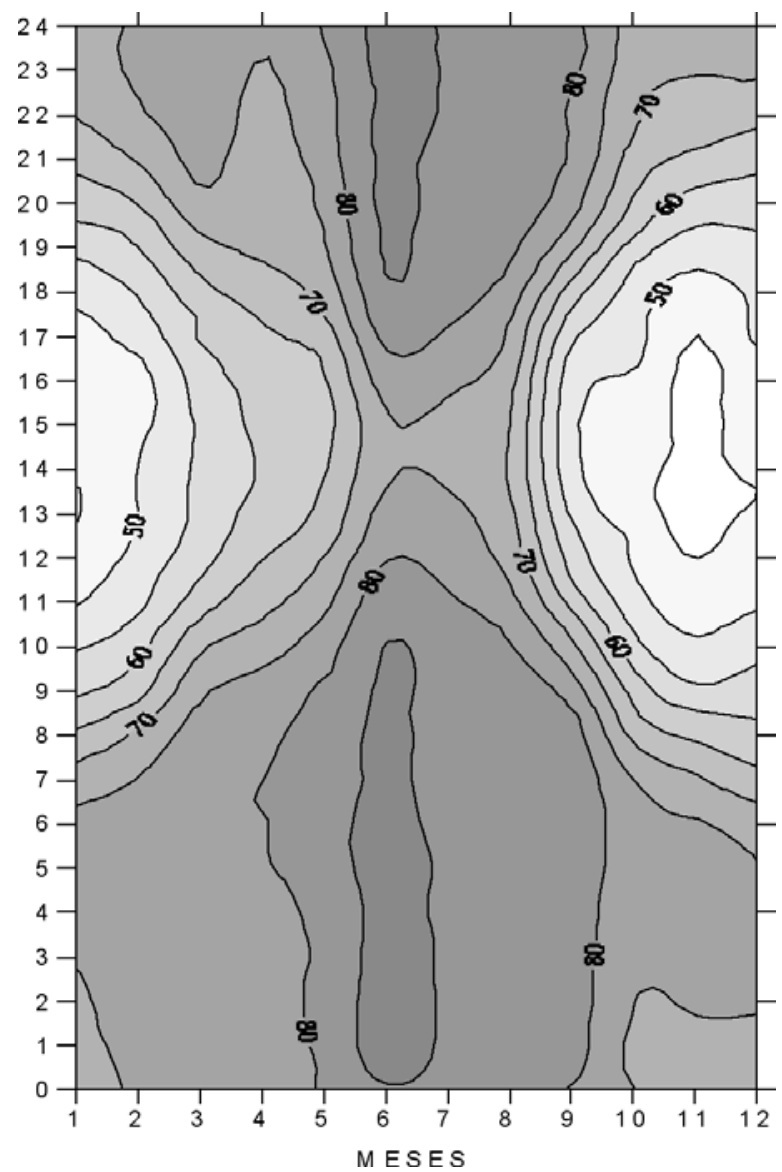

Fig. 17. Diagrama de isolíneas de humedad relativa diaria y mensual.

\subsection{Viento}

El viento en Posesión alcanzó un promedio anual de 5,8 m/s, con máximos mensuales de 7,8 $\mathrm{m} / \mathrm{s}$ en noviembre y promedios mínimos de $4,1 \mathrm{~m} / \mathrm{s}$ en septiembre. Debido a la dinámica de los sistemas atmosféricos involucrados, este comportamiento no es general para todos los años, pudiendo presentarse promedios mensuales máximos y mínimos en cualquiera de los otros meses.

TABLA 10. Promedios y extremos de velocidad en eventos de media hora.

\begin{tabular}{crrrrrrrrrrrrr}
\hline & ENE & FEB & MAR & ABR & MAY & JUN & JUL & AGO & SEP & OCT & NOV & DIC & Año \\
\hline Media & 6,5 & 6,1 & 5,1 & 7,1 & 5,1 & 4,2 & 5,1 & 5,3 & 4,1 & 6,4 & 6,9 & 7,5 & 5,8 \\
Max. & 15,5 & 16,2 & 12,2 & 16,5 & 13,5 & 13,7 & 14,3 & 14,8 & 13,0 & 19,8 & 19,8 & 16,9 & 19,8 \\
Min. & 0,24 & 0,12 & 0,02 & 0,36 & 0,22 & 0,00 & 0,01 & 0,19 & 0,14 & 0,11 & 0,10 & 0,60 & 0,0 \\
Racha & 21,7 & 23,0 & 20,0 & 23,3 & 19,8 & 19,8 & 20,4 & 20,3 & 17,9 & 27,5 & 27,4 & 22,2 & 27,5 \\
\hline
\end{tabular}

Los máximos promedios alcanzados en periodos de media hora, llegaron a los $19,8 \mathrm{~m} / \mathrm{s} \mathrm{el}$ 4 de octubre entre las 11:30 h y las $12: 00 \mathrm{~h}$ y el 12 de noviembre entre las 21:30 h y las 22:00 h. De acuerdo a los registros, solamente se produjo un evento de media hora en que el promedio del velocidad fue cero y ocurrió el 21 de junio entre las 00:00 h y las 00:30 h. El resto de los meses registraron valores mínimos que pudieron ser medidos con el sensor como los ocurridos en julio y marzo con $0,01 \mathrm{~m} / \mathrm{s}$ y $0,02 \mathrm{~m} / \mathrm{s}$, respectivamente. 
TABLA 11. Distribución de frecuencia mensual de velocidades del viento.

\begin{tabular}{rrrrrrrrrrrrr}
\hline $\mathrm{m} / \mathrm{s}$ & ENE & FEB & MAR & ABR & MAY & JUN & JUL & AGO & SEP & OCT & NOV & DIC \\
\hline $0-1$ & 24 & 52 & 79 & 17 & 76 & 174 & 51 & 66 & 114 & 69 & 56 & 9 \\
$1-2$ & 83 & 104 & 161 & 64 & 129 & 226 & 178 & 170 & 248 & 142 & 106 & 65 \\
$2-3$ & 132 & 127 & 146 & 85 & 157 & 242 & 178 & 192 & 242 & 111 & 82 & 98 \\
$3-4$ & 128 & 134 & 165 & 81 & 204 & 162 & 161 & 159 & 183 & 110 & 106 & 116 \\
$4-5$ & 175 & 163 & 177 & 111 & 203 & 134 & 181 & 120 & 160 & 135 & 127 & 129 \\
$5-6$ & 173 & 153 & 224 & 147 & 209 & 123 & 194 & 150 & 139 & 134 & 151 & 126 \\
$6-7$ & 166 & 159 & 154 & 182 & 139 & 107 & 182 & 183 & 130 & 147 & 123 & 136 \\
$7-8$ & 137 & 127 & 131 & 180 & 136 & 107 & 127 & 155 & 100 & 177 & 148 & 142 \\
$8-9$ & 133 & 120 & 117 & 177 & 134 & 79 & 86 & 110 & 67 & 112 & 100 & 158 \\
$9-10$ & 94 & 88 & 82 & 147 & 52 & 27 & 67 & 81 & 24 & 96 & 90 & 155 \\
$10-11$ & 78 & 57 & 32 & 102 & 24 & 19 & 49 & 55 & 17 & 93 & 99 & 86 \\
$11-12$ & 89 & 31 & 18 & 54 & 13 & 28 & 25 & 18 & 11 & 62 & 104 & 77 \\
$12-13$ & 38 & 20 & 2 & 53 & 9 & 8 & 5 & 15 & 5 & 38 & 78 & 99 \\
$13-14$ & 19 & 19 & 0 & 19 & 3 & 4 & 3 & 8 & 0 & 24 & 49 & 49 \\
$14-15$ & 14 & 24 & 0 & 13 & 0 & 0 & 1 & 6 & 0 & 10 & 12 & 31 \\
$15-16$ & 5 & 13 & 0 & 6 & 0 & 0 & 0 & 0 & 0 & 16 & 2 & 10 \\
$16-17$ & 0 & 1 & 0 & 2 & 0 & 0 & 0 & 0 & 0 & 3 & 2 & 2 \\
$17-18$ & 0 & 0 & 0 & 0 & 0 & 0 & 0 & 0 & 0 & 4 & 3 & 0 \\
$18-19$ & 0 & 0 & 0 & 0 & 0 & 0 & 0 & 0 & 0 & 2 & 1 & 0 \\
$19-20$ & 0 & 0 & 0 & 0 & 0 & 0 & 0 & 0 & 0 & 3 & 1 & 0 \\
\hline
\end{tabular}

La velocidad máxima instantánea (racha) alcanzada por el viento llegó a los $27,5 \mathrm{~m} / \mathrm{s}$, el 4 de octubre a las 11:24 h. Otra racha similar ocurrió en el 12 de noviembre a las 11:55 h y alcanzó a los $27,4 \mathrm{~m} / \mathrm{s}$. La tabla 10 muestra los valores mensuales medios y extremos alcanzados por el viento durante el 2008.

De la totalidad de las mediciones de viento, la gran mayoría de las velocidades ocurrieron entre valores que van desde $1 \mathrm{~m} \mathrm{~s}^{-1}$ a $10 \mathrm{~m} \mathrm{~s}^{-1}$, representando un $84 \%$ del total del tiempo. La frecuencia máxima se ubicó en el intervalo 5 a $6 \mathrm{~m} / \mathrm{s}$, alcanzando a unos 1923 casos, equivalentes a un 10,9 \% del total de mediciones en el año 2008. La tabla 11 muestra la distribución de frecuencias de velocidad del viento (en intervalos de $1 \mathrm{~m} \mathrm{~s}^{-1}$ ) para cada mes de 2008, mientras que la figura 18 muestra la distribución de frecuencias de velocidad del viento anual.

Debido a los altos promedios alcanzados durante todo el año, i.e., todos los meses con valores medios superiores a los $4 \mathrm{~m} \mathrm{~s}^{-1}$, resulta interesante evaluar la cantidad de energía proporcionada por el viento en esta localidad, de acuerdo a la metodología expuesta anteriormente. Para esto consideramos una densidad del aire basada en la presión $(\mathrm{hPa})$ y la temperatura media anual, aplicando la formula (8). Con valores de $99.4 \mathrm{hPa}$ y 7,3 $3^{\circ} \mathrm{C}(280,3)$, la densidad del aire es de $1,24 \mathrm{~kg} \mathrm{~m}^{-3}$. 


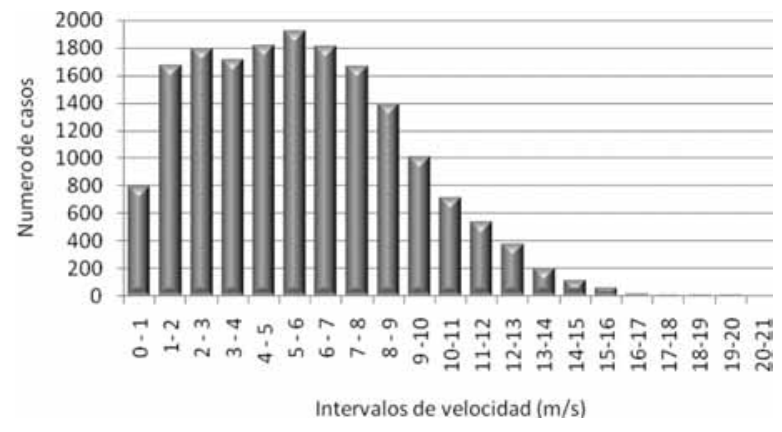

Fig. 18. Distribución de frecuencia anual de las velocidades del viento.

Reemplazando los valores de frecuencia absoluta anual (divididos por 2, ya que se trata de eventos de media hora) para cada intervalo de velocidad, representado por su marca de clase, en la formula (6) se obtiene la energía del viento por intervalo, representando la sumatoria de éstos el total de energía para el año 2008 en Posesión y a una altura de $10 \mathrm{~m} \mathrm{~s}$. $\mathrm{n}$. s.

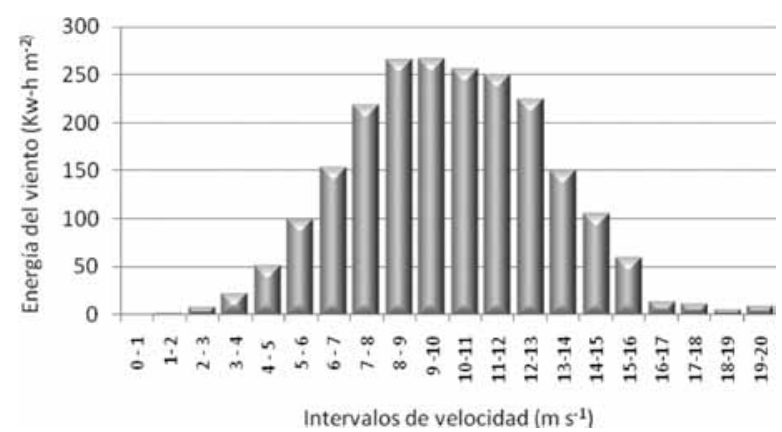

Fig. 19 Energía del viento en Posesión durante el año 2008.

De acuerdo a los cálculos realizados y a lo mostrado en la figura 19, la energía total aportada por el viento durante el 2008 en Posesión y a una altura de $10 \mathrm{~m} \mathrm{~s}$. n. s. alcanzó a la cifra de 2.172,2 $\mathrm{m}^{-2}$. De este total, la mayor energía la entregaron las velocidades comprendidas entre los intervalos $8-9 \mathrm{~m} \mathrm{~s}^{-1}$ y $9-10 \mathrm{~m} \mathrm{~s}^{-1}$. De hecho el 86,9\% de esta energía queda comprendida entre el intervalo 6 a $15 \mathrm{~m} \mathrm{~s}^{-1}$.

$\mathrm{Al}$ igual que la temperatura y la humedad relativa del aire, el viento muestra una dependencia de la radiación solar y su correlación es casi directa, es decir, cuando la radiación solar aumenta, también aumentan los promedios del viento. De esta manera, se establece que los mayores valores medios ocurren hacia las horas del mediodía y hacia la estación de verano, en tanto que los valores mínimos se producen en horas de la noche y/o madrugada y hacia el invierno. La figura 18 nuestra las isopletas de viento a través del día y por cada mes del año 2008.

La velocidad del viento también depende de las posiciones que toman los centros dinámicos de altas y bajas presiones en la alta atmósfera y a nivel de superficie. Estas situaciones le dan un cierto matiz al comportamiento del viento, el que difiere un tanto con el de la temperatura y la humedad. En el 2008 se produjo un alto promedio en abril, aunque en este mes la radiación está disminuyendo rápidamente hasta el invierno y con relación a la de los meses de verano. Durante el mes de junio, cuando la radiación solar está en su mínimo regional, las variaciones del viento diario apenas muestran un alza en las horas del mediodía, evidenciando que la radiación solar es el motor de la dinámica del aire

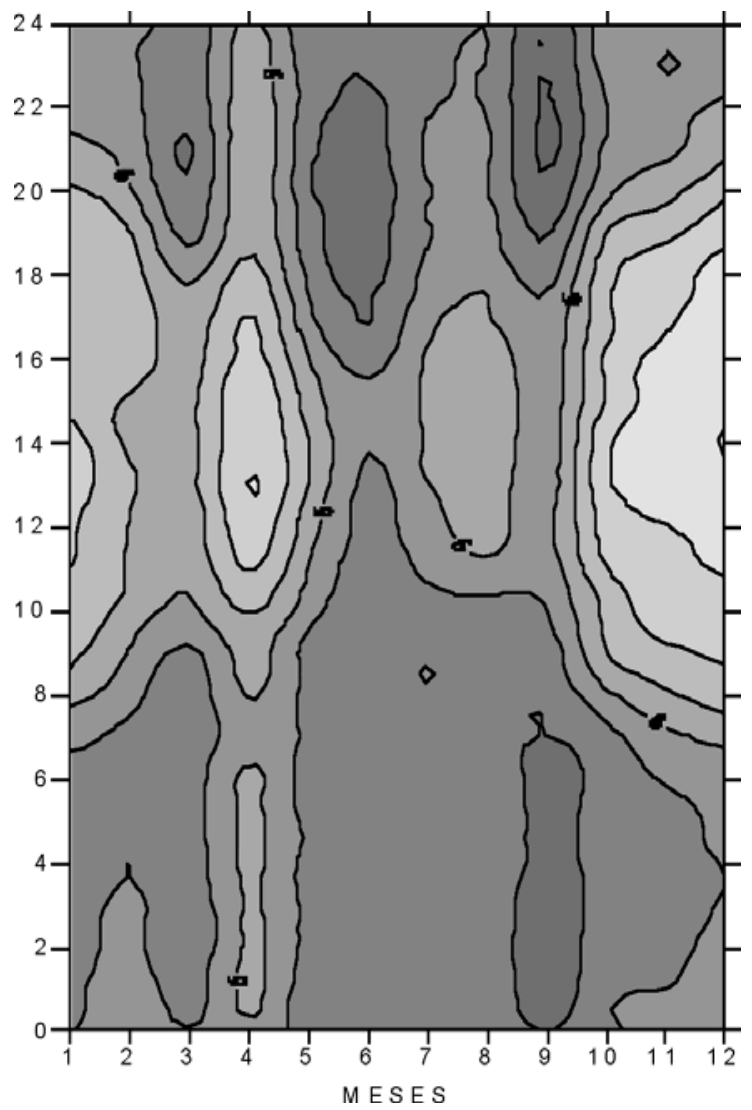

Fig. 20. Isopletas de viento en Posesión durante el año 2008 


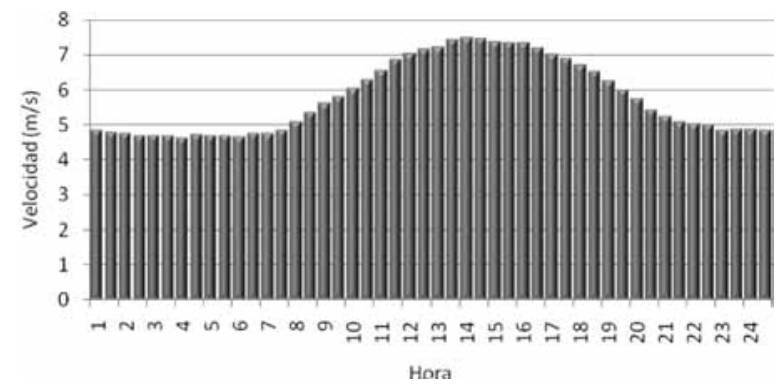

Fig. 21. Distribución diaria de la velocidad del viento para el año 2008.
(Endlicher 1991). La figura 20 muestra las isopletas de viento diarias y por mes durante el 2008.

Sin embargo, en el promedio anual, la curva diaria es muy definida y se distribuye con velocidades menores en horas de la noche y madrugada, mientras que los valores más altos se producen en horas del mediodía. Desde luego que este patrón del comportamiento diario del viento se cumple más exactamente en los meses de verano y se pierde en los meses de invierno al igual que la intensidad de la radiación solar. La figura 20 muestra los promedios anuales del viento a lo largo del día, durante el 2008.

aunque también fueron importantes las velocidades provenientes del suroeste. En la tabla 12 se muestra la frecuencia absoluta de casos (periodos de media hora) de viento en ocho direcciones y el total de casos analizadas por cada mes.

TABLA 12. Frecuencia absoluta de casos por cada dirección

\begin{tabular}{ccrrrrrrrr}
\hline & N & NE & \multicolumn{1}{c}{ E } & \multicolumn{1}{c}{ SE } & \multicolumn{1}{c}{ S } & SW & W & NW & SUMA \\
\hline ENE & 183 & 85 & 5 & 12 & 50 & 622 & 337 & 194 & 1488 \\
FEB & 227 & 115 & 31 & 22 & 67 & 477 & 254 & 199 & 1392 \\
MAR & 159 & 56 & 37 & 31 & 67 & 392 & 379 & 367 & 1488 \\
ABR & 150 & 53 & 12 & 7 & 81 & 498 & 434 & 205 & 1440 \\
MAY & 295 & 69 & 13 & 14 & 87 & 288 & 326 & 396 & 1488 \\
JUN & 321 & 57 & 4 & 4 & 8 & 208 & 371 & 467 & 1440 \\
JUL & 219 & 205 & 91 & 16 & 28 & 264 & 316 & 349 & 1488 \\
AGO & 218 & 120 & 98 & 145 & 56 & 196 & 348 & 307 & 1488 \\
SEP & 382 & 138 & 10 & 87 & 71 & 161 & 229 & 362 & 1440 \\
OCT & 214 & 56 & 16 & 13 & 7 & 300 & 545 & 337 & 1488 \\
NOV & 214 & 84 & 6 & 20 & 17 & 358 & 504 & 237 & 1440 \\
DIC & 175 & 61 & 3 & 1 & 35 & 623 & 399 & 191 & 1488 \\
\hline SUMA & 2757 & 1099 & 326 & 372 & 574 & 4387 & 4442 & 3611 & 17568 \\
\hline
\end{tabular}

De acuerdo a esta tabla, la dirección predominante es el oeste con un total de 4.442 casos, equivalente al 25,3\% del total anual, seguido del suroeste con 4.387 casos, equivalente al $25 \%$ del total anual de casos. Estas dos direcciones superan la mitad de los registros de viento para el 2008. Sin embargo, esta frecuencia se debe analizar más detalladamente para descubrir que en la dirección noroeste predominan los vientos en el rango de las velocidades bajas, mientras que en la dirección oeste predominan las velocidades medias y las velocidades altas la predominancia en el 2008 fue del suroeste.

En general, durante el año 2008 las velocidades bajas del viento, es decir, velocidades mayores que cero y hasta $4 \mathrm{~m} \mathrm{~s}^{-1}$ de promedio, llegaron al 33,9 $\%$ del total del tiempo, mientras que las velocidades medias, es decir, entre 4 y $8 \mathrm{~m} \mathrm{~s}^{-1}$ como promedio, alcanzaron al $41,1 \%$ del total y las velocidades altas, i.e., las de promedios mayores de $8 \mathrm{~m} \mathrm{~s}^{-1}$, llegaron al $25 \%$. 
TABLA 13. Frecuencia relativa (\%) de velocidades para tres rangos

\begin{tabular}{crrrrrrrrr}
\hline Rango & $\mathrm{N}$ & $\mathrm{NE}$ & $\mathrm{E}$ & $\mathrm{SE}$ & $\mathrm{S}$ & $\mathrm{SW}$ & $\mathrm{W}$ & $\mathrm{NW}$ & Suma \\
\hline $\mathrm{V}<4 \mathrm{~m} \mathrm{~s}^{-1}$ & 6.9 & 1.8 & 0.9 & 1.1 & 1.1 & 3.7 & 6.7 & 11.8 & 33.9 \\
$4<\mathrm{V}<8 \mathrm{~m} \mathrm{~s}^{-1}$ & 6.0 & 2.9 & 0.9 & 1.0 & 1.6 & 10.5 & 11.3 & 6.9 & 41.1 \\
$\mathrm{~V}>8 \mathrm{~m} \mathrm{~s}^{-1}$ & 2.8 & 1.5 & 0.1 & 0.1 & 0.6 & 10.8 & 7.3 & 1.8 & 25.0 \\
\hline Suma & 15.7 & 6.3 & 1.9 & 2.1 & 3.3 & 25.0 & 25.3 & 20.6 & 100.0 \\
\hline
\end{tabular}

Del total de tiempo con velocidades bajas, un $11,8 \%$ lo hicieron de la dirección noroeste, seguido de la dirección norte con un 6,0 \% y del oeste con un $6,7 \%$. En las velocidades medias, que ocupan el mayor porcentaje del tiempo en el año, la dirección predominante fue del oeste con un $11,3 \%$ seguido del suroeste con un $10,5 \%$ del total. Finalmente las velocidades altas mostraron un predominio en la dirección suroeste con un 10,8 \% del total del tiempo, seguido de la dirección oeste con un 7,3\%.

O

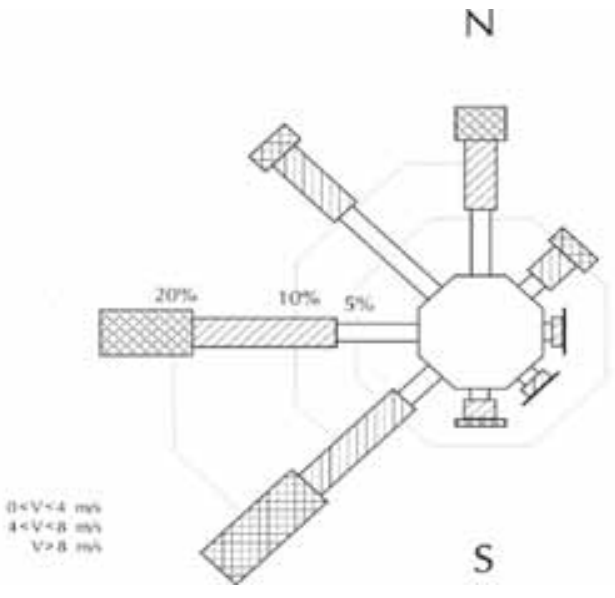

Fig. 22. Rosa de frecuencia de viento 2008 para Posesión.
La figura 22 muestra las direcciones del viento y tres rangos de velocidad para cada una de éstas. En cada dirección se puede medir el porcentaje de horas con respecto al total registrado durante el año y a la vez se puede medir, en porcentaje, el rango en que el viento sopló en cada dirección.

A diferencia de Punta Arenas, esta rosa de viento muestra que en todas las direcciones se producen velocidades en los tres rangos establecidos, aunque las de los cuadrantes este, sureste y sur, la frecuencia de velocidades altas es mínima.

La distribución de velocidades por cada dirección muestra diferencias importantes entre ellas. Mientras en las direcciones suroeste y oeste las mayores frecuencias se encuentran en los rangos 5 a $11 \mathrm{~m} \mathrm{~s}^{-1}$ y 3 a $9 \mathrm{~m} \mathrm{~s}^{-1}$ respectivamente, en la dirección noroeste la frecuencia que predomina es la de velocidades entre 1 a $2 \mathrm{~m} \mathrm{~s}^{-1}$. Por su parte, E la dirección norte, si bien muestra una frecuencia máxima en el rango 1 a $2 \mathrm{~m} \mathrm{~s}^{-1}$, también la frecuencia de velocidades medias es importante, entre los 4 a $8 \mathrm{~m} \mathrm{~s}^{-1}$. En el resto de direcciones, la distribución de velocidades no es trascendente debido al bajo porcentaje de tiempo que significan, en relación al total. La tabla 14 muestra la frecuencia de velocidades para cada dirección en intervalos de $1 \mathrm{~m} \mathrm{~s}^{-1}$. 
TABLA 14. Distribución de frecuencias de velocidad por dirección

\begin{tabular}{lrrrrrrrr}
\hline $\mathrm{m} / \mathrm{s}$ & $\mathrm{N}$ & $\mathrm{NE}$ & $\mathrm{E}$ & $\mathrm{SE}$ & \multicolumn{1}{c}{$\mathrm{S}$} & $\mathrm{SW}$ & $\mathrm{W}$ & $\mathrm{NW}$ \\
\hline $0-1$ & 201 & 40 & 32 & 36 & 29 & 47 & 59 & 343 \\
$1-2$ & 431 & 63 & 43 & 38 & 27 & 134 & 185 & 755 \\
$2-3$ & 322 & 104 & 38 & 55 & 47 & 208 & 447 & 571 \\
$3-4$ & 256 & 105 & 40 & 58 & 86 & 266 & 490 & 408 \\
$4-5$ & 274 & 107 & 51 & 41 & 75 & 413 & 483 & 371 \\
$5-6$ & 304 & 142 & 46 & 43 & 91 & 397 & 537 & 363 \\
$6-7$ & 238 & 143 & 28 & 37 & 82 & 506 & 486 & 288 \\
$7-8$ & 234 & 125 & 29 & 47 & 40 & 526 & 471 & 195 \\
$8-9$ & 177 & 104 & 18 & 16 & 41 & 523 & 365 & 149 \\
$9-10$ & 126 & 72 & 1 & 1 & 25 & 410 & 297 & 71 \\
$10-11$ & 89 & 55 & 0 & 0 & 8 & 281 & 222 & 56 \\
$11-12$ & 44 & 22 & 0 & 0 & 6 & 255 & 181 & 22 \\
$12-13$ & 45 & 3 & 0 & 0 & 7 & 201 & 104 & 10 \\
$13-14$ & 13 & 4 & 0 & 0 & 5 & 109 & 64 & 2 \\
$14-15$ & 3 & 7 & 0 & 0 & 2 & 72 & 24 & 3 \\
$15-16$ & 0 & 2 & 0 & 0 & 3 & 33 & 13 & 1 \\
$16-17$ & 0 & 1 & 0 & 0 & 0 & 6 & 3 & 0 \\
$17-18$ & 0 & 0 & 0 & 0 & 0 & 0 & 6 & 1 \\
$18-19$ & 0 & 0 & 0 & 0 & 0 & 0 & 1 & 2 \\
$19-20$ & 0 & 0 & 0 & 0 & 0 & 0 & 4 & 0 \\
\hline
\end{tabular}

Variación de la temperatura, precipitación, presión atmosférica y humedad relativa, de acuerdo a la dirección del viento

El viento, tanto en su velocidad como en su dirección, parece tener influencias importantes en las otras variables atmosféricas en lo relativo a sus valores a través del año (Schneider et al. 2003). Si se separan en tres tipos principales de patrones de tiempo a escala sinóptica, se obtiene el grupo de los westerlies, definido por los vientos provenientes de las direcciones suroeste, oeste y noroeste; el grupo de los northerlies definido por los vientos del norte, noreste y este; y el grupo de los southerlies definido por los vientos de las direcciones sureste y sur (Schneider et al. 2003). Otra opción es analizar la variación en cada dirección del viento y reagruparla de acuerdo a los grupos definidos para comparación con otras localidades.

Si se analiza la variación de las temperaturas en función de la dirección de los vientos, tanto el aire como el suelo muestran que los mayores promedios se producen cuando predomina la corriente suroeste, mientras que los promedios más bajos ocurren cuando el viento sopla desde el este. Cabe tener en cuenta aquí que el principal elemento que hace variar la temperatura durante el año es la radiación solar que en definitiva es la que define las diferentes estaciones. La figura 23 muestra las variaciones de la temperatura en función de la dirección del viento durante el año 2008 en Posesión.
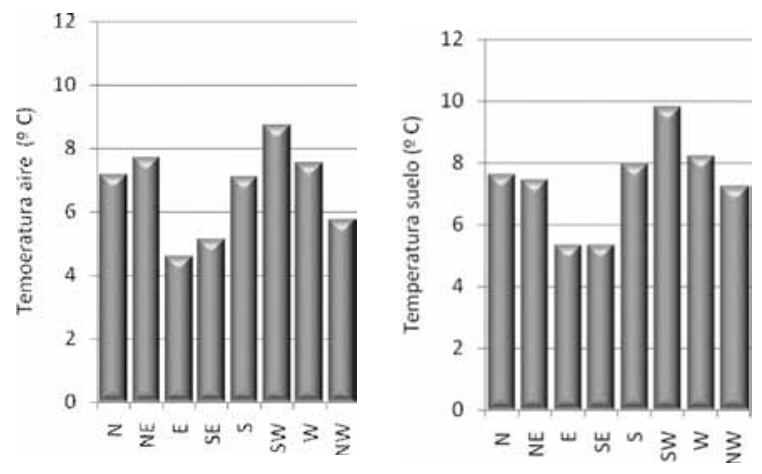

Fig. 23. Variaciones de temperatura según la dirección del viento.

De acuerdo con la figura 24, que muestra los montos anuales de lluvia para cada dirección del 
viento alcanzados durante el 2008 en la localidad de Posesión, las mayores precipitaciones ocurrieron de la direcciones norte y suroeste, seguido de las direcciones este y noroeste. Por su lado, los menores montos de precipitación se produjeron de las direcciones sureste y sur.

Con respecto a la variación de la presión atmosférica en relación a la dirección del viento, los promedios más altos ocurrieron de la dirección este, mientras que los valores medios, notoriamente más bajos, fueron de la dirección oeste. La figura 25 muestra los valores medios anuales de la presión atmosférica para cada dirección del viento, durante el 2008 en Posesión.

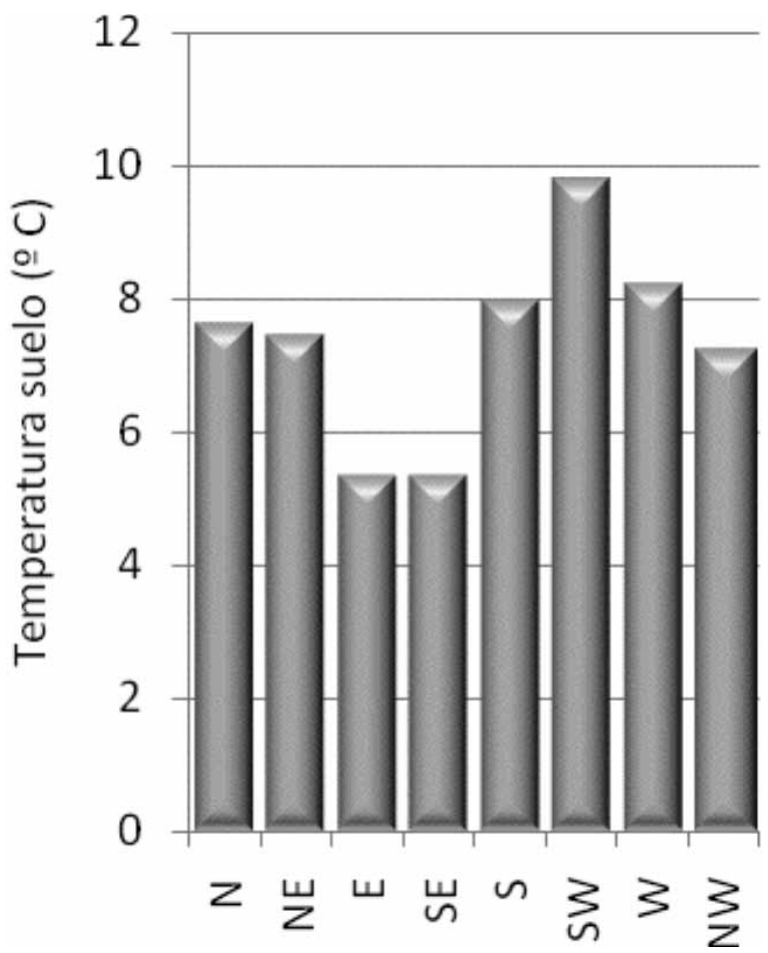

Fig.24. Montos anuales de precipitación según la dirección del viento.

Al igual que la precipitación y la presión atmosférica, los valores medios de humedad relativa son más altos cuando los vientos provienen de la dirección este, los cual justifica el mayor monto de precipitación en esta dirección Por su parte los valores de humedad mínimos se presentaron de la dirección suroeste, seguidas del oeste. La figura 26 muestra las variaciones promedio anual de la

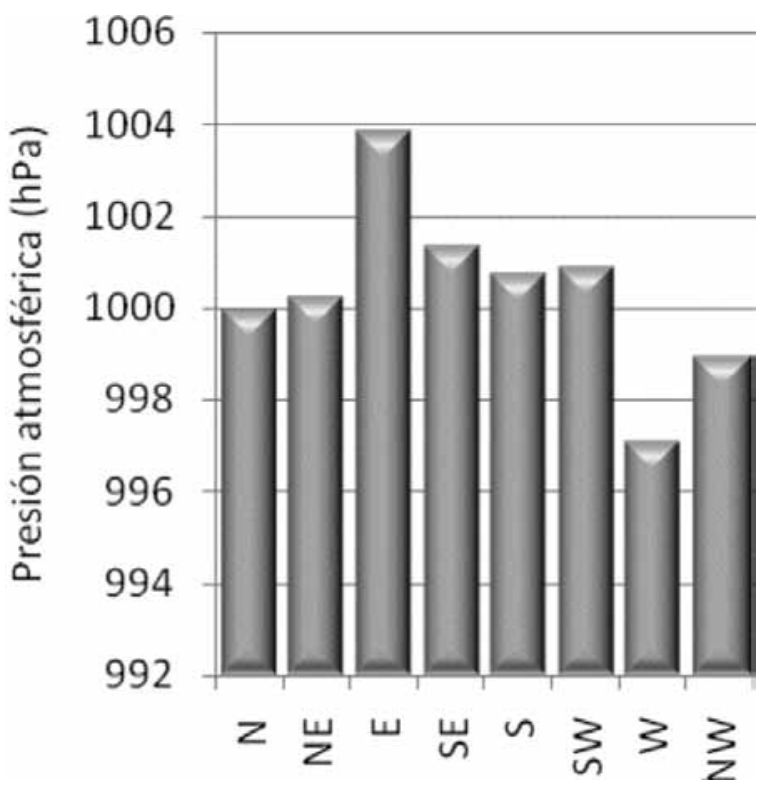

Fig. 25. variaciones de la presión según la dirección del viento.

humedad relativa para cada dirección del viento durante el 2008 en Posesión.

Comparación con Punta Arenas

La localidad de Punta Arenas dispone para

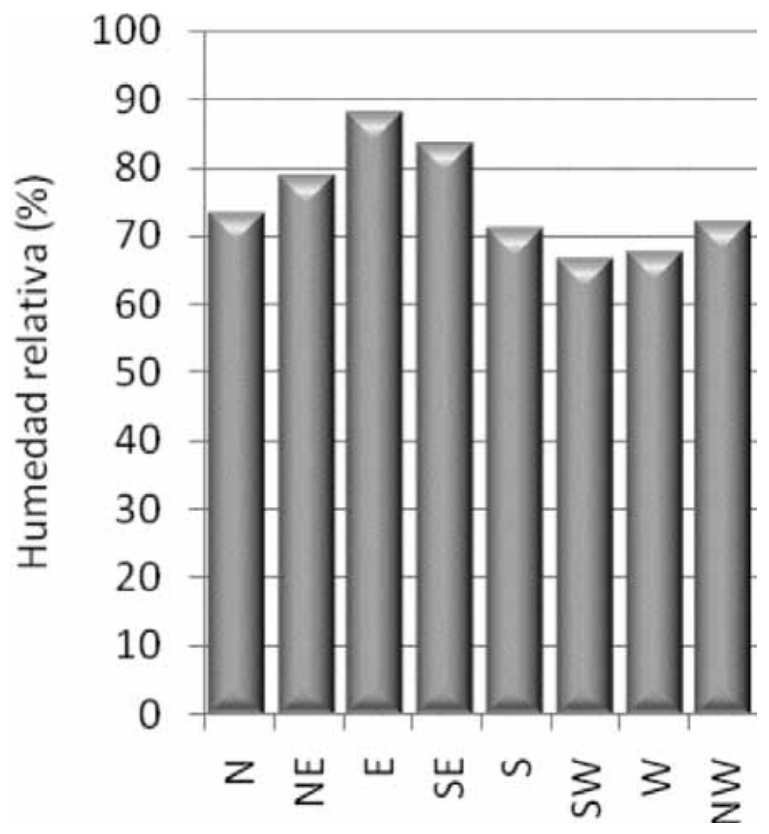

Fig. 26. Variaciones de la humedad según la dirección del viento. 

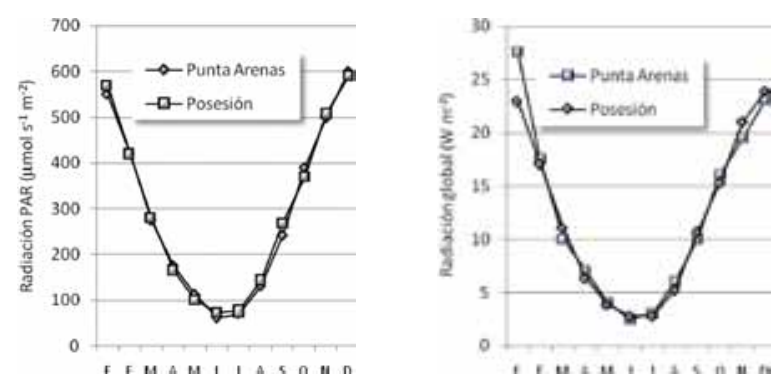

Fig. 27. Comparación de las radiaciones PAR y global entre Punta Arenas y Posesión.

el año 2008 de series de tiempo de igual resolución temporal en la mayoría de las variables estudiadas aquí. Esto hace interesante la comparación entre estas localidades en un mismo periodo.

El promedio anual de radiación PAR alcanzó en Punta Arenas fue de 292,4 $\mu \mathrm{mol} \mathrm{s}^{-1} \mathrm{~m}^{-2}$ (Butorovic 2008) es decir, $4,6 \mu \mathrm{mol} \mathrm{s}^{-1} \mathrm{~m}^{-2}$ menos que el promedio alcanzado en Posesión. Los meses que marcaron la diferencia a favor de Posesión fueron enero y septiembre, mientras que el promedio de Punta Arenas que superó a Posesión ocurrió en octubre.

La radiación global por su parte presentó un promedio en Posesión inferior en $0,3 \mathrm{~W} \mathrm{~m}^{-2}$ que el obtenido para Punta Arenas (Butorovic 2008) y las principales diferencias ocurrieron en enero y noviembre, aunque en sentidos opuestos. La figura 27 muestra la comparación de la radiación PAR y global entre Punta Arenas y Posesión.

Aunque las temperaturas muestran variaciones

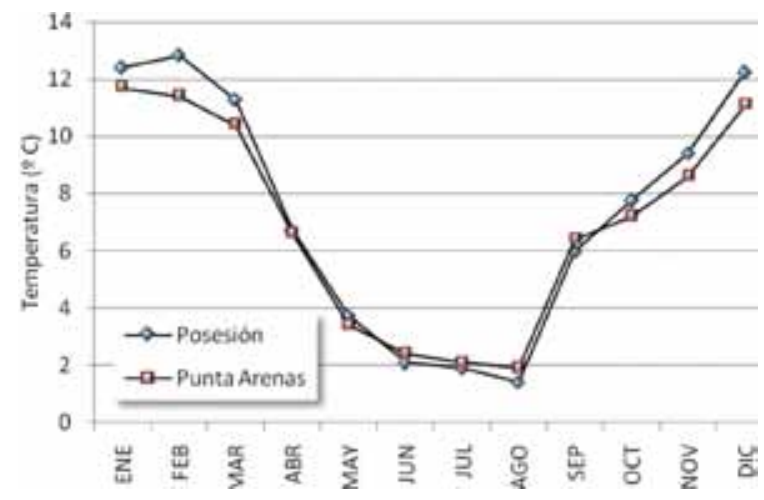

Fig. 28. Comparación de la temperatura media mensual entre Posesión y Punta Arenas.

similares, la amplitud en ambas localidades es diferente. La mayor de ellas se produce en la localidad de Posesión, mostrando mayores valores medios en verano y menores promedios en los meses de invierno. La figura 28 muestra los valores medios mensuales para ambas localidades.

Las temperaturas de estas localidades están altamente correlacionadas. La tabla 12 muestra los valores del coeficiente de correlación de promedios diarios por cada mes entre ambas localidades. En general todos los meses muestran una correlación alta, inclusive a nivel de promedios cada media hora. Se observa una leve baja durante los meses de invierno, coincidente con la disminución de la velocidad del viento en esa época del año, la que al ser menor, transporta en forma menos eficaz las condiciones de Punta Arenas a la localidad de Posesión.

TABLA 12. Coeficiente de correlación (R) de temperaturas medias entre Punta Arenas y Posesión

\begin{tabular}{ccccccccccccc}
\hline Media c/ & ENE & FEB & MAR & ABR & MAY & JUN & JUL & AGO & SEP & OCT & NOV & DIC \\
1/2 hora & 0,83 & 0,77 & 0,77 & 0,83 & 0,80 & 0,74 & 0,72 & 0,71 & 0,83 & 0,81 & 0,82 & 0,82 \\
Un día & 0,90 & 0,87 & 0,89 & 0,92 & 0,93 & 0,83 & 0,84 & 0,79 & 0,86 & 0,91 & 0,89 & 0,88 \\
\hline
\end{tabular}

Esta correlación aumenta aún más si es que se analiza con un cierto retardo en la localidad de Posesión y esto puede deberse a la predominancia del los vientos del oeste que requieren de un tiempo determinado para transportar las condiciones de tiempo desde Punta Arenas a Posesión. Esto lleva a considerar que el porcentaje que no se correlaciona se debe a corrientes provenientes de otras direcciones distintas a los westerlies (Endlicher \& Santana 1988, Schneider et al. 2003), como las de las direcciones este y norte, cuyas condiciones presentes en Posesión no llegan influir en Punta Arenas. Aquí cabe mencionar que las altas correlaciones de la temperatura entre localidades distantes en Magallanes ya han sido mencionadas por varios autores (Schneider et al. 2003, Santana et al. 2006, 2007).

Estas altas correlaciones permiten inferir que las variaciones de largo plazo entre estas localidades son similares, de manera que la estadística histórica de las variaciones térmicas 
en Punta Arenas puede ser extrapolada a esta localidad, por supuesto, considerando los rangos de variación de Posesión.

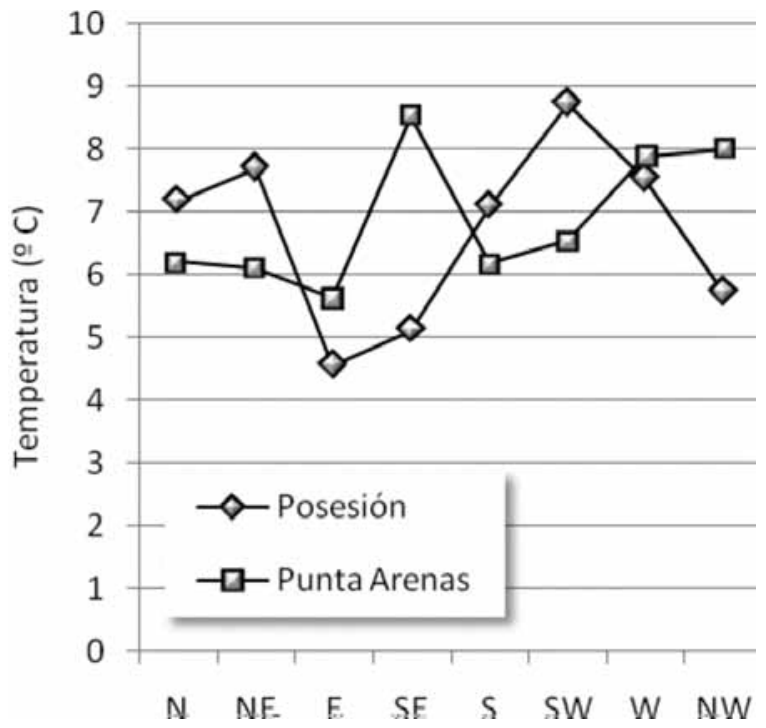

Fig. 29. Comparación de las temperaturas del aire según la dirección del viento.

Considerando las variaciones de la temperatura respecto de la dirección del viento, a diferencia de Posesión ya analizado en el estudio del viento de esa localidad, en Punta Arenas las temperaturas más altas ocurren cuando el viento sopla del cuadrante sureste, norte y oeste. La figura 27 muestra la comparación de los promedios mensuales de temperatura en ambas localidades para el año 2008.

La precipitación de Punta Arenas durante el 2008 alcanzó a los 535,6 mm (Butorovic 2008), es decir unos 260,5 mm más que en Posesión, lo cual está de acuerdo a lo establecido por diversos autores, que la precipitación e Punta Arenas duplica la de Posesión (Jerez \& Arancibia 1972, Hoffman 1975).

También se observan diferencias entre Punta Arenas y Posesión cuando se analizan los montos de precipitación en función de la dirección del viento. Mientras en Posesión predominan los montos más altos de las direcciones norte y suroeste, en Punta Arenas éstos lo hacen de las direcciones oeste y noroeste. Aunque en ambas localidades se observa una disminución de los montos en inviernos, en Punta Arenas los montos mínimos se produjeron de la dirección suroeste, mientras que en Posesión los mínimos provienen del sur y sureste. La figura 30 muestra los montos por dirección del viento en ambas localidades para su comparación.

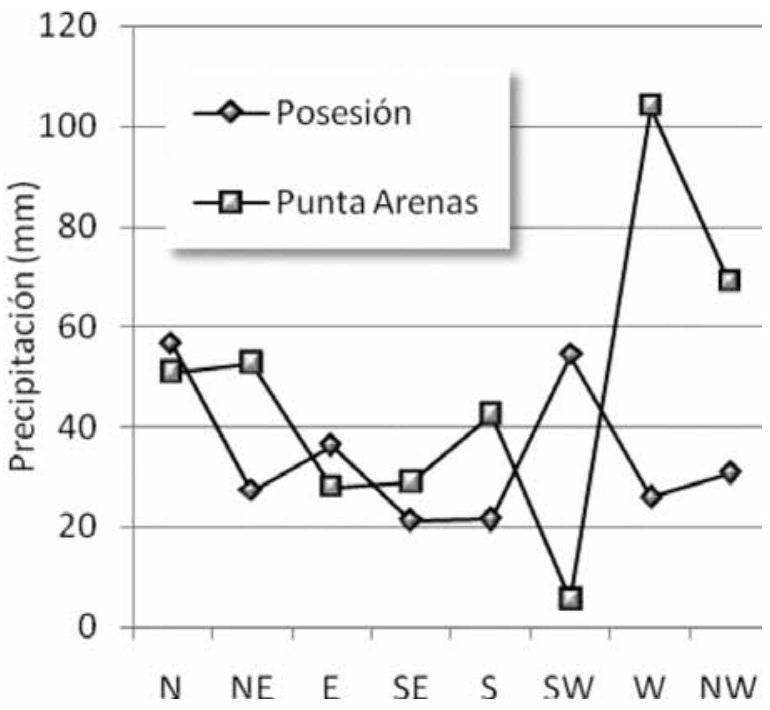

Fig. 30. Comparación de las precipitaciones según la dirección del viento.

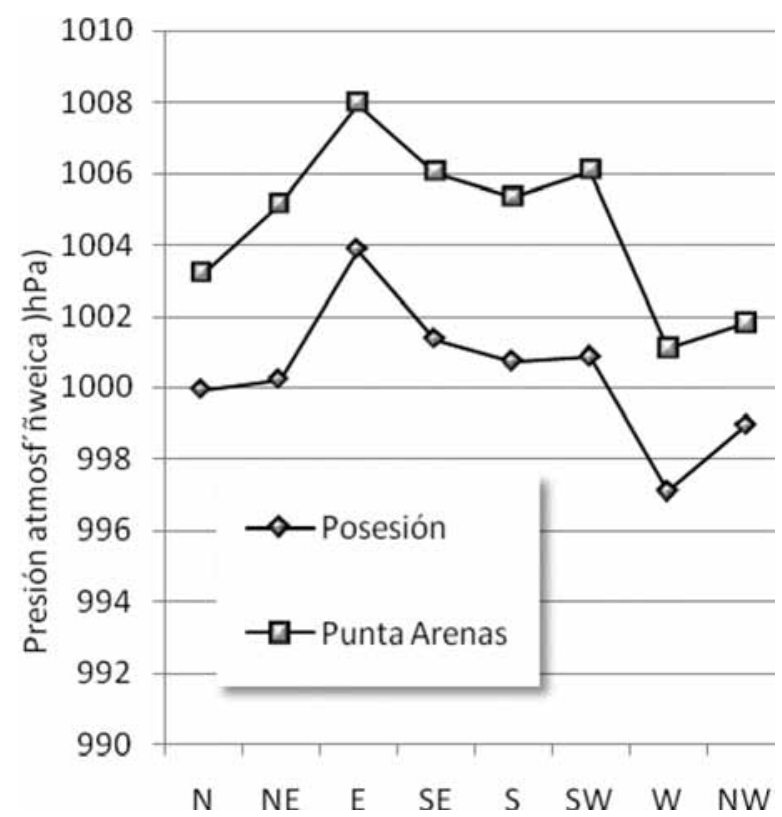

Fig. 31. Comparación de la presión atmosférica según la dirección del viento.

Con respecto a la presión atmosférica, ya se mencionó que esta es una variable de macro escala 


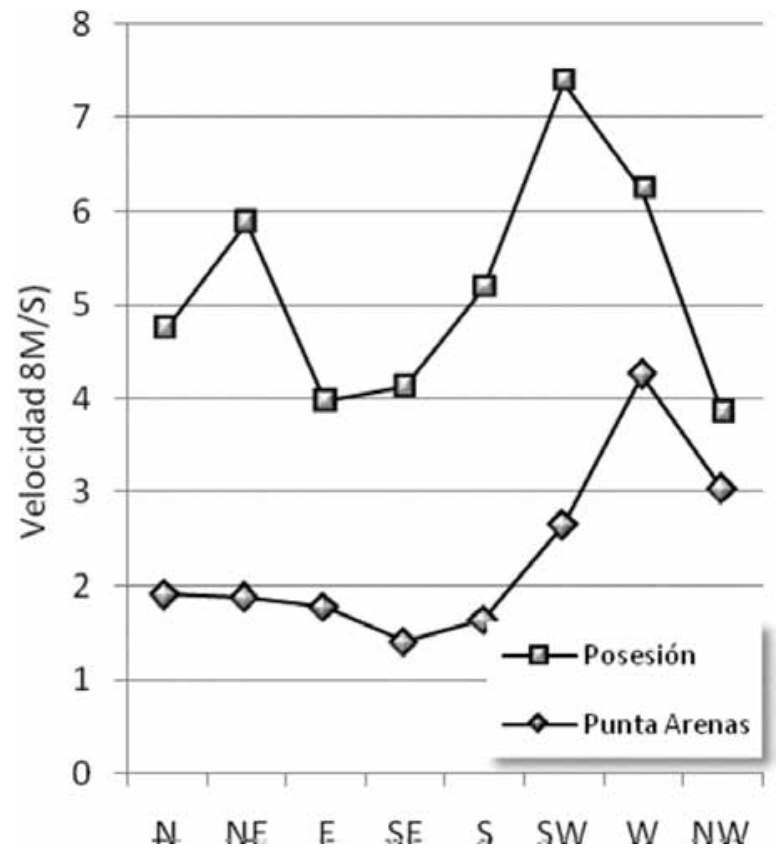

Fig. 32. Comparación de la velocidad del viento por dirección.

y su variación es similar en grandes regiones. Dentro de Magallanes las diferencias no alcanzan a ser importantes y éstas se deben principalmente a diferencias de altitud de las estaciones donde esta variable se mide. La figura 31 muestra las variaciones de la presión en función de la dirección del viento, mostrando ambas localidades, patrones similares. La diferencia entre estas se deben principalmente a la diferencia de altura sobre el nivel del mar en que se encuentra cada una de ellas. Mientras Punta Arenas está a unos $6 \mathrm{~m} \mathrm{~s}$. n. m. (Santana 2005, Butorovic 2008), la altitud de Posesión es de unos $40 \mathrm{~m} \mathrm{~s}$. n. m.

Con respecto al viento, de manera general se observa una tendencia similar, aunque con algunos matices. Si bien, los mayores promedios provienen de la dirección oeste en Punta Arenas, en Posesión lo hacen desde la dirección suroeste. Una diferencia notable lo constituyen los vientos provenientes del noreste que, al contrario de Punta Arenas, alcanzan promedios notablemente mayores a sus direcciones vecinas inmediatas.

La diferencia en los promedios en cada dirección se debe fundamentalmente a la diferencia en la altura del sensor, que en el caso de Posesión es a $10 \mathrm{~m} \mathrm{~s}$. n. s. mientras que en Punta Arenas el sensor de la AWS está ubicado a solo $2,5 \mathrm{~m} \mathrm{~s}$. n. s.

\section{AGRADECIMIENTOS}

Se agradece a la Empresa Nacional del Petróleo (ENAP), y a su permanente vínculación con la Universidad de Magallanes, la cual permitió que personal de la Planta Posesión, y en particular los Sres. Juan Carlos Paredes, Nelson Menéndez, José Tascón, Godofredo Torres, Rafael Estrada, Jorge Ojeda, Ariel Pontigo, Vicente Tenore y Raúl Oyarzún, pudieran colaborar en la instalación de una estación automática de última generación, y cuya ayuda fue fundamental para el desarrollo del presente estudio.

\section{LITERATURA CITADA}

Butorovic, N. 2009. Resumen meteorológico año 2008. Estación Jorge Schythe. Anales Instituto Patagonia (Chile), 37(1):133-140.

Chuvieco, E. 2002. Teledetección Ambiental - La observación de la tierra desde el espacio. Editorial Ariel S.A. Primera edición, Madrid, España.

Endlicher, W. 1991. Zur Klimageographie und Klimaökologie von Südpatagonien. 100 Jahre klimatologische Messungen in Punta Arenas. Freiburger Geographische Hefte. University of Freiburg, Germany. Vol. 32, 161-211.

Endlicher, W. \& A. Santana 1988. El clima del sur de la Patagonia y sus aspectos ecológicos. Un siglo de mediciones climatológicas en Punta Arenas. Anales Instituto Patagonia (Chile), Serie Cs. Nat. 18: 57-86.

Fuenzalida, P. H. 1950. Clima: En: Geografía Económica de Chile, CORFO, I: 188-254.

Fuenzalida, P, H. 1967, Clima: En: Geografía Económica de Chile, Texto refundido, CORFO, 98-152.

Hoffmann. J., 1975. Atlas climático de América del Sur: mapas de temperaturas y precipitaciones medias. World Meteorological Organization (OMM).

Jerez M. \& M. Arancibia 1972. Trazado de isoyetas del sector centro oriental de la provincia de Magallanes. Ediciones del Instituto de la Patagonia. Serie Monografías $N^{\circ}$ 4. Punta Arenas, Chile.

Long, C. E., 1980. Discovering The Universe. Harper \& Row Publishiers. San Francisco, 
USA. $511 \mathrm{pp}$.

Mathew, S. 2006. Wind Energy. Fundamentals, Resource Analysis and Economics.

Springer-Verlag Berlin Heidelberg. 246 pp.

Page, C. H. \& P. Vigoureux 1977. The International system of unit (SI) Nat. Bur. Of

Standards, Special Publ, 330, 2ed edn, US, Govt, Printing Office, Washington DC, USA.

Pisano, E. 1977. Fitogeografía de Fuego-Patagonia Chilena. I. Comunidades vegetales entre las latitudes $52^{\circ}$ y $57^{\circ} \mathrm{S}$. Anales Instituto Patagonia (Chile) 8: 121-250.

Redlinger, R., P. Andersen \& P. Morthorst 2002. Wind Energy in the 21st Century.

Economics, Policy, Technology and the Changing Electricity Industriy. UNEP. 245 pp.

Retallack, B. J. 1973. Compendio de apuntes para la formación de personal meteorológico de la clase IV. Vol. 1, Ciencias de la Tierra. OMM $N^{\circ}$ 266, Ginebra, Suiza, 219 pp.

Santana, A., C. Porter, N. Butorovic \& C. Olave 2007. Características climáticas del canal Brecknock en los 5430' S de latitud, Magallanes, Chile. Anales Instituto Patagonia (Chile), 35 (1): 5 - 18

Santana, A. 2006. Resumen meteorológico año 2005. Anales Instituto Patagonia (Chile), 34: $81-90$
Santana, A. 2007. Resumen meteorológico año 2006. Anales Instituto Patagonia (Chile),35 (1): 81-89

Santana, A., C. Porter, N. Butorovic \& C. Olave 2006. Primeros antecedentes climatológicos de estaciones automáticas (AWS) en el canal Beagle, Magallanes, Chile. Anales Instituto Patagonia (Chile), 34: 5-20.

Schneider, C., M. Glaser, R. Kilian, A. Santana, N. Butorovic \& G. Casassa 2003.

Weather observations across the Southern Andes at $53^{\circ} \mathrm{S}$. Physical Geography 24 (2):97-119.

Sola, J. C. 1979, Astronomía. Explorando el universo. Editorial Ramón Sopena, S. A. Barcelona. España. 535 pp.

Strahler, A. N. 1979. Geografía Física. Ediciones Omega, Barcelona. 767 pp. Obra original: Physical Geography. John Wiley and Song Inc. Traducido por A. M. Guilló y J. F. Albert.

Valko, P. 1978. Wind: Häufigkeit, Zeitverlauf, Persistenz von Windgeschwindigkeit und Windrichtung für verschiedene Orte der Schweiz. Bern und Stuttgart.

Weischet, W. 1985. Climatic constraints for the development of the far south of Latin America. Geo Journal, 11:79-87.

Weischet, W. 1996. Regionale Klimatologie Teil 1, Die Neue Welt. Amerika Neuseeland, Australien. 